NBER WORKING PAPER SERIES

\title{
STRATEGIC INTERACTION AMONG HETEROGENEOUS PRICE-SETTERS IN AN ESTIMATED DSGE MODEL
}

\author{
Olivier Coibion \\ Yuriy Gorodnichenko \\ Working Paper 14323 \\ http://www.nber.org/papers/w14323 \\ NATIONAL BUREAU OF ECONOMIC RESEARCH \\ 1050 Massachusetts Avenue \\ Cambridge, MA 02138 \\ September 2008
}

The authors thank Bob Barsky, Angus Chu, Bill Dupor, Chris House, Ed Knotek, Peter Morrow, Serena Ng, Phacharapot Nuntramas, Oleg Korenok, Matthew Shapiro, Eric Sims, Mark Watson, an anonymous referee, and seminar participants at the University of Michigan and North American Econometric Society Meeting for helpful comments. The authors also wish to thank the Robert V. Roosa Fellowship and Rackham Dissertation Fellowship for financial support, the SciClone Computational Cluster (College of William and Mary) and Center for Advanced Computing (University of Michigan) for computational support. The views expressed herein are those of the author(s) and do not necessarily reflect the views of the National Bureau of Economic Research.

NBER working papers are circulated for discussion and comment purposes. They have not been peerreviewed or been subject to the review by the NBER Board of Directors that accompanies official NBER publications.

(C) 2008 by Olivier Coibion and Yuriy Gorodnichenko. All rights reserved. Short sections of text, not to exceed two paragraphs, may be quoted without explicit permission provided that full credit, including (C) notice, is given to the source. 
Strategic Interaction Among Heterogeneous Price-Setters In An Estimated DSGE Model

Olivier Coibion and Yuriy Gorodnichenko

NBER Working Paper No. 14323

September 2008, Revised April 2009

JEL No. E3,E5

\begin{abstract}
$\underline{\text { ABSTRACT }}$
We consider a DSGE model in which firms follow one of four price-setting regimes: sticky prices, sticky-information, rule-of-thumb, or full-information flexible prices. The parameters of the model, including the fractions of each type of firm, are estimated by matching the moments of the observed variables of the model to those found in the data. We find that sticky-price firms and sticky-information firms jointly account for over $80 \%$ of firms in the model, with the rest largely accounted for by rule-of-thumb firms. We compare the performance of our hybrid model to pure sticky-price and sticky-information models along various dimensions, including monetary policy implications.
\end{abstract}

\author{
Olivier Coibion \\ Department of Economics \\ College of William and Mary \\ 115 Morton Hall \\ Williamsburg, VA 23188 \\ ocoibion@wm.edu \\ Yuriy Gorodnichenko \\ Department of Economics \\ 549 Evans Hall \#3880 \\ University of California, Berkeley \\ Berkeley, CA 94720-3880 \\ and NBER \\ ygorodni@econ.berkeley.edu
}




\section{Introduction}

The nature of price-setting decisions made by firms has long played a pivotal role underlying controversies in macroeconomics. Whereas real business cycle (RBC) models assume that firms with full information are free to set prices optimally at all times, New Keynesian models are typically defined by departures from the assumption of flexible prices. ${ }^{1}$ Recent work has also emphasized the implications of deviating from the assumption of full-information in price setting. ${ }^{2}$ This paper is motivated by the idea that a single assumption about firms' price-setting decision process may be insufficient to adequately capture macroeconomic dynamics by missing potentially important interactions among heterogeneous firms. Indeed, firm-level evidence indicates striking heterogeneity in price setting as well as significant information costs. ${ }^{3}$ We develop and estimate a dynamic stochastic general equilibrium model that allows for four commonly assumed price-setting sectors to coexist and interact via their price-setting decisions. Our results indicate that 1) the hybrid model fits the data substantially better than any of the models consisting solely of one type of firm; 2) sticky-price and sticky-information firms account for more than $80 \%$ of all firms in the hybrid model; 3) neither rule-of-thumb nor flexible-price full-information firms are important to match the moments of the data; 4) strategic interaction of different price setting practices is qualitatively and quantitatively important.

To assess the relative importance of heterogeneity in the price-setting behavior of firms, we consider a continuum of monopolistic producers of intermediate goods, divided into four segments, each of which uses a different price-setting approach. These include sticky-prices, stickyinformation, rule-of-thumb, and full-information flexible-price firms. ${ }^{4}$ This setup is nested in an otherwise standard New Keynesian model with a representative consumer and a central bank. The

\footnotetext{
${ }^{1}$ See Kydland and Prescott (1982) for the seminal presentation of a classical RBC model and Woodford (2003) for an indepth presentation of New Keynesian models.

2 Sims' (2003) rational inattention model, Woodford's (2001) imperfect common knowledge, and Mankiw and Reis' (2002) sticky-information models are prime examples.

${ }^{3}$ Empirical work typically finds a large amount of heterogeneity in the frequency of price changes by firms, as well as in the source of costs to changing prices (information vs menu costs). Bils and Klenow (2004) and Dhyne et al (2005), for example, find that there are large differences in durations between price changes across sectors. Taylor (1999) cites the example of frozen orange juice prices changing every two weeks while magazine prices change every three years. Zbaracki et al (2004) and Fabiani et al (2005) report significant information costs.

${ }^{4}$ Sticky-price firms are modeled a la Calvo (1983), sticky-information firms are as in Mankiw and Reis (2002), and ruleof-thumb firms always update prices by last period's inflation rate, as in Barsky and Kilian (2001).
} 
model also allows for a stochastic trend in technology and non-zero trend inflation. ${ }^{5}$ The parameters of the model, including the share of each type of firm, are estimated jointly using a method of moments approach. This delivers a set of predicted moments for the observable variables that can be directly compared to those of the data.

Because we allow for these four types of firms to coexist, our model nests many price-setting models considered in the literature. For example, sticky-price models are frequently augmented with rule-of-thumb firms to better match the inflation inertia observed in the data, but the relative importance of forward-looking versus backward-looking behavior has been much debated. ${ }^{6}$ Our result that sticky-price firms account for approximately sixty percent of firms is consistent with the findings of much of this literature, but the fact that rule-of-thumb firms are ruled out in favor of sticky-information firms implies that the role previously assigned to rule-of-thumb firms in explaining backward-looking behavior in the New Keynesian Phillips Curve (NKPC) is instead likely due to the presence of sticky-information firms.

Flexible-price full-information firms are included to capture the potential importance of heterogeneity in rates at which prices and information are updated. Bouakez et al (2006), Carvalho (2006) and Aoki (2001) demonstrate that heterogeneity in price stickiness across sectors affects the dynamics and optimal monetary policy of a sticky price model respectively. By including flexible price firms, our model nests a simple case of such heterogeneity. The fact that these types of firms receive an estimated share of only $8 \%$ indicates that heterogeneity of this sort is relatively unimportant to match the moments of the data.

The presence of sticky-price, sticky-information, and rule-of-thumb firms also nests empirical work to assess the empirical support for the NKPC versus the Sticky Information Phillips Curve (SIPC). While results have been either ambiguous or favored the NKPC (Korenok (2008), Kiley (2007) and Coibion (forthcoming)), most of this literature has assumed that either the NKPC or SIPC (or their weighted average) form the true models without allowing for coexistence of different price setting mechanisms. ${ }^{7}$ We build on this approach by allowing for both sticky-price and sticky-information firms to coexist and interact via strategic complementarities in price-setting.

\footnotetext{
${ }^{5}$ We allow for trend inflation because it has non-trivial effects on the dynamics of the sticky price model (Ascari 2004, Coibion and Gorodnichenko 2008). In addition, we show in section 2.5 that trend inflation has interesting steady state effects on the relative price levels of different price setting sectors and therefore plays an important role in our model.

${ }^{6}$ Gali and Gertler (1999), Linde (2005), and Rudd and Whelan (2006) are examples.

${ }^{7}$ Andres et al (2005) is an exception by finding that the sticky-information model is statistically preferred to a stickyprice model.
} 
Our finding that both types of firms are required to best match the data thus calls into question much of this previous work focused only on one model or the other.

By considering a hybrid model with sticky-prices and sticky-information, this paper is most closely related to recent work by Dupor et al (forthcoming), Knotek (2008), and Klenow and Willis (2007), each of which superimpose delayed information updating as in Mankiw and Reis (2002) upon firms already facing nominal rigidities: menu costs in Knotek (2008) and Klenow and Willis (2007) and time-dependent updating in Dupor et al (forthcoming). ${ }^{8}$ Each finds empirical evidence for sticky-prices and sticky-information. Thus, our results complement their findings. However, our approach differs from theirs in three important aspects. First, whereas each of these papers considers models in which all firms are subject to both sticky prices and sticky information, our model allows for sticky-price and sticky-information firms to coexist and interact via strategic complementarities in price-setting, but does not allow for any firm to have both sticky-prices and sticky-information. While we view our approach as a better approximation to the fact that the relative importance of pricing and informational rigidities varies across firms, and thus are likely to be best modeled via different pricing assumptions, whether sticky-prices and sticky-information are best integrated vertically (as in Klenow and Willis (2007), Knotek (2008) and Dupor et al (forthcoming)) or horizontally is an as-of-yet unexplored empirical question. Second, our model is more general since it nests sticky-price, sticky-information, and rule-of-thumb firms as well as flexible-price fullinformation firms, whereas Klenow and Willis (2007), Knotek (2008) and Dupor et al (forthcoming) exclude either rule-of-thumb or flexible-price full-information or both types of firms. Third, neither Knotek (2008) nor Dupor et al (forthcoming) use fully-specified DSGE models for their empirical results and thus are not able to explore the implications of heterogeneous price-setting for sources of business cycles, optimal policy and so on.

To estimate our DSGE model, we make use of the dynamic auto- and cross-covariances of observable variables. These moments provide important insights about the lead-lag structure of economic relationships. By comparing the ability of the estimated hybrid model and estimated pure models to match these moments of the data, one contribution of the paper is being able to assess why the data prefer our hybrid model over pure sticky-price or sticky-information models. For example, the moments of the data indicate that inflation leads output growth and interest rates. This stylized

\footnotetext{
${ }^{8}$ In Knotek (2008), information updates follow a Poisson process as in Mankiw and Reis (2002), but subject to a maximum number of periods after which information is automatically updated.
} 
fact is the primary reason why sticky-firms account for such a large fraction of firms since stickyprices induce more-forward looking behavior than alternative price-setting setups.

We also consider the implications of our results for optimal monetary policy. While much work has been devoted to studying optimal monetary policy for sticky-price models, and some work has extended this type of analysis to sticky-information, Kitamura (2008) is the only other paper which considers optimal monetary policy in a hybrid sticky-price and sticky-information model and does so using the vertically integrated hybrid model of Dupor et al (forthcoming). ${ }^{9}$ Based on our estimated DSGE model, we find that there could be significant gains in welfare if the central bank used policy rules different from the estimated Taylor rule. In particular, our simulations indicate dramatic improvements when the central banker has a more aggressive response to inflation or incorporates an element of price level targeting in his or her reaction function. We show that using pure sticky-price or sticky-information models can greatly mislead the central banker about potential gains from using alternative policy rules in the presence of heterogeneous price setting. The fact that Kitamura (2008) reaches a similar conclusion using an alternative integration of price and informational rigidities supports the notion that accounting for both types of rigidities has important monetary policy implications which are not adequately addressed in either pure sticky-price or pure sticky-information models. Finally, we find that there is little penalty from using a policy with a response to inflation that is uniform across sectors relative to policy rules with differential responses.

The structure of the paper is as follows. In section 2, we present the model. Section 3 discusses the empirical methodology. Our benchmark estimates, discussion, and robustness analysis are in section 4. Section 5 considers the implications of our results for optimal monetary policy while section 6 concludes.

\section{Model}

The model has three principal types of agents: consumers, firms, and the central bank. The consumer's problem is modeled as a representative agent with internal habit formation. ${ }^{10}$ Production is broken into final goods and intermediate goods. Production of the final goods is perfectly competitive whereas the intermediate goods are produced by a continuum of monopolistic

\footnotetext{
${ }^{9}$ See Woodford (2003) for optimal monetary policy based on sticky-prices and Ball et al (2005) for the stickyinformation model.

${ }^{10}$ Ravina (2004) and Grishchenko (2005) provide empirical evidence supporting internal habit formation over external habit formation.
} 
producers. The latter follow different price-setting rules. Finally, the central bank sets interest rates according to a Taylor (1993) rule.

\subsection{Consumer's Problem}

The representative agent seeks to maximize the present discounted value of current and future utility levels

$$
\max _{\left\{C_{t+j}, N_{t+j}(i), H_{t+j}\right\}_{j=0}^{\infty}} E_{t} \sum_{j=0}^{\infty} \beta^{j}\left[e^{g_{t+j}} \ln \left(C_{t+j}-h C_{t+j-1}\right)-\frac{1}{1+1 / \eta} \int_{0}^{1} N_{t+j}^{1+1 / \eta}(i) d i\right],
$$

where $C_{t}$ is consumption at time $t, N_{t}(i)$ is labor supplied to intermediate goods firm $i, h$ is the degree of internal habit formation, $\eta$ is the Frisch labor supply elasticity, $\beta$ is the discount factor, and $g_{t}$ is a shock to the marginal utility of consumption. We allow for labor to be supplied individually to specific firms to generate stronger strategic complementarity in price setting. ${ }^{11}$ Because consumption and labor are separable in the utility function, we impose that consumption enters in a logarithmic form to be consistent with a balanced growth path. Each period, the consumer faces the following budget constraint

$$
C_{t+j}+\frac{H_{t+j}}{P_{t+j}} \leq \int_{0}^{1} N_{t+j}(i) \frac{W_{t+j}(i)}{P_{t+j}} d i+\frac{H_{t+j-1}}{P_{t+j}} R_{t+j-1}+T_{t+j},
$$

where $H_{t}$ is the stock of risk-free bonds held at time $t$ and $R_{t}$ is the gross nominal interest rate earned on bonds in the subsequent period. $W_{t}(i)$ is the nominal wage earned from labor supplied to intermediate goods firm $i$ and $T_{t}$ consists of profits returned to the consumer. Finally, $P_{t}$ is the price of the consumption good at time $t$.

Defining $\Lambda_{t}$ to be the shadow value of wealth, the first-order conditions with respect to each control variable are

$$
\begin{array}{ll}
\text { Consumption } & \Lambda_{t}=\frac{e^{g_{t}}}{C_{t}-h C_{t-1}}-\beta h E_{t} \frac{e^{g_{t+1}}}{C_{t+1}-h C_{t}}, \\
\text { Labor Supply } & N_{t}^{1 / \eta}(i)=\Lambda_{t}\left(W_{t}(i) / P_{t}\right), \\
\text { Bonds } & \Lambda_{t}=\beta E_{t}\left[\Lambda_{t+1} R_{t}\left(P_{t} / P_{t+1}\right)\right] .
\end{array}
$$

${ }^{11}$ See Woodford (2003, Chapter 3) for a discussion of why strategic complementarity is needed in New Keynesian models. 


\subsection{Production}

The final good is produced by a perfectly competitive industry using a continuum of intermediate goods through a Dixit-Stiglitz aggregator

$$
Y_{t}=\left(\int_{0}^{1} Y_{t}(j)^{(\theta-1) / \theta} d j\right)^{\theta /(\theta-1)}
$$

This yields the following price level

$$
P_{t}=\left(\int_{0}^{1} P_{j}(j)^{1-\theta} d j\right)^{1 /(1-\theta)}
$$

The demand facing an intermediate producer $j$ is then given by

$$
Y_{t}(j)=\left(P_{t}(j) / P_{t}\right)^{-\theta} Y_{t} \text {. }
$$

We assume that intermediate goods producers have a production function that is linear in labor $Y_{t}(j)=A_{t} N_{t}(j) .^{12}$ Despite the presence of firm-specific labor supply, we assume that firms treat wages as exogenously determined. The optimal frictionless price $\left(P_{t}^{\#}\right)$ is a markup $\mu \equiv \theta /(\theta-1)$ over firm-specific nominal marginal costs, where the latter are given by $M C_{t}(j)=W_{t}(j) / A_{t}$. Eliminating the firm-specific elements of marginal cost by substituting in the labor supply condition and the firm-level demand yields the following relationship between real firm-specific marginal costs and aggregate marginal costs

$$
\frac{M C_{t}(j)}{P_{t}}=\frac{\left(P_{t}(j) / P_{t}\right)^{-\omega \theta}}{D_{t}} \frac{M C_{t}}{P_{t}}
$$

where $\omega \equiv \eta^{-1}, M C_{t} / P_{t} \equiv \frac{\left(Y_{t} / A_{t}\right)^{\omega}}{\Lambda_{t} A_{t}\left(1-\tau_{N, t}\right)} \int_{0}^{1}\left(P_{t}(i) / P_{t}\right)^{-\omega \theta} d i$, and $D_{t}=\int_{0}^{1}\left(P_{t}(i) / P_{t}\right)^{-\omega \theta} d i$ is a measure of the dispersion of prices across firms. We can then write a firm's instantaneous optimal desired relative price as

$$
\left(\frac{P_{t}^{\#}}{P_{t}}\right)^{1+\omega \theta}=\left(\frac{\mu}{D_{t}}\right) \frac{M C_{t}}{P_{t}},
$$

Since there is no capital in the model, the goods market clearing condition is simply $Y_{t}=C_{t}$.

\footnotetext{
${ }^{12}$ We omit capital from the model for tractability. Woodford (2003, p. 372-378) argues that the dynamics of the standard pricing model without capital is very similar to the dynamics of the model with capital.
} 


\subsection{Price-Setting Behavior}

Intermediate good producing firms are assumed to be in one of four price-setting sectors: sticky prices, sticky-information, rule-of-thumb, or flexible prices. We assume, without loss of generality, that firms of the same pricing sector are grouped into segments so that the price level can be written as

$$
P_{t}=\left[\int_{0}^{s_{1}} P_{t}^{s p}(j)^{1-\theta} d j+\int_{s_{1}}^{s_{2}+s_{1}} P_{t}^{s i}(j)^{1-\theta} d j+\int_{s_{2}+s_{1}}^{s_{3}+s_{2}+s_{1}} P_{t}^{r o t}(j)^{1-\theta} d j+\int_{s_{3}+s_{2}+s_{1}}^{1} P_{t}^{f l e x}(j)^{1-\theta} d j\right]^{1 /(1-\theta)},
$$

where $s p$, si, rot, and flex are indices for sticky-price, sticky-information, rule-of-thumb, and flexible price firms respectively. Importantly, firms are otherwise identical in the sense that a firm in a given sector is the same competitor to all other firms symmetrically irrespective of whether they are in the same sector or not. The weighting parameters $s_{1}, s_{2}$, and $s_{3}$ are the fractions of firms that belong to the sticky-price, sticky-information, and rule-of-thumb sectors respectively. Flexible-price firms are assigned the remaining mass of $s_{4}=1-s_{1}-s_{2}-s_{3}$. Firms cannot switch sectors. Defining the price level specific to sector $k$ as $P_{t}^{k} \equiv\left[s_{k}^{-1} \int_{s_{k-1}+s_{k-2}+\ldots}^{s_{k}+s_{k-1}+\ldots} P_{t}(j)^{1-\theta} d j\right]^{1 /(1-\theta)}$, we can rewrite the aggregate price level as

$$
P_{t}=\left[s_{1} P_{t}^{s p^{1-\theta}}+s_{2} P_{t}^{s i^{1-\theta}}+s_{3} P_{t}^{r o t^{1-\theta}}+s_{4} P_{t}^{f l e x^{1-\theta}}\right]^{1 /(1-\theta)} .
$$

Sticky price firms: These firms face a constant probability $1-\delta_{s p}$ of being able to change their price each period. A firm with the ability to change its price at time $t$ will choose a reset price $B_{t}$ to maximize the expected present discounted value of future profits

$$
B_{t}(j)=\arg \max _{B_{t}(j)} \sum_{j=0}^{\infty} \delta_{s p}^{j} E_{t}\left\{Q_{t, t+j}\left(B_{t}(j)-M C_{t+j}(j)\right) Y_{t+j}(j)\right\}
$$

where $Q_{t, t+j}$ is the nominal stochastic discount factor between times $t$ and $t+j$ and firm-specific marginal costs and output are as before. Taking the first-order condition and replacing firm-specific marginal costs and output with their corresponding aggregate terms yields the optimality condition

$$
\sum_{j=0}^{\infty} \delta_{s p}^{j} E_{t}\left\{Q_{t, t+j} Y_{t+j} P_{t+j}^{\theta}\left[B_{t}^{1+\omega \theta}-\mu M C_{t+j} P_{t+j}^{\theta \omega} / D_{t+j}\right]\right\}=0
$$

so that all firms with the opportunity to reset prices choose the same value of $B_{t}$. The price level for sticky price firms obeys

$$
P_{t}^{s p}=\left[\left(1-\delta_{s p}\right) B_{t}^{1-\theta}+\delta_{s p} P_{t-1}^{s p^{1-\theta}}\right]^{1 /(1-\theta)} .
$$


Sticky-Information Firms: These firms face a Poisson process for updating their information sets, with the probability of getting new information in each period given by $1-\delta_{s i}$. In every period, firms set prices freely given their information set. The profit-maximization problem at time $t$ for firm $j$ which last updated its information set at time $t-k$ is then

$$
P_{t \mid t-k}^{s i}(j)=\arg \max _{P} E_{t-k}\left[\left(P-M C_{t}(j)\right) Y_{t}(j)\right]
$$

where firm-specific marginal costs and demand are determined as before. This yields the solution that a firm $j$ that last updated its information $k$ periods ago sets its time- $t$ price equal to $P_{t \mid t-k}^{s i}(j)=E_{t-k} P_{t}^{\#}$. Hence, the price level for sticky information firms is

$$
P_{t}^{s i}=\left[\left(1-\delta_{s i}\right) \sum_{j=0}^{\infty} \delta_{s i}^{j}\left(E_{t-j} P_{t}^{\#}\right)^{1-\theta}\right]^{1 /(1-\theta)}
$$

Rule-of-Thumb Firms: These firms always change their prices by the previous period's inflation rate. $^{13}$ Hence, the price level for the rule-of-thumb sector follows

$$
P_{t}^{r o t}=P_{t-1}^{r o t}\left(P_{t-1} / P_{t-2}\right) \text {. }
$$

Flexible Price/Information Firms: These firms are always free to change prices and have complete information. They thus always set prices equal to the instantaneously optimal price. The price level for flexible price firms is then just $P_{t}^{\text {flex }}=P_{t}^{\#}$.

\subsection{Shocks}

We assume the following shock processes. First, technology shocks follow a random walk with drift

$$
\log A_{t}=\log a+\log A_{t-1}+\varepsilon_{a, t}
$$

where $\varepsilon_{a, t}$ are independently distributed with mean zero and variance $\sigma_{a}^{2}$. Preference shocks follow a stationary $\mathrm{AR}(1)$ process

$$
g_{t}=\rho_{g} g_{t-1}+\varepsilon_{g, t}
$$

\footnotetext{
${ }^{13}$ Technically this implies that the relative price level of rule-of-thumb firms is indeterminate in a stationary steady-state. This can be avoided by assuming a Poisson probability $1-\delta_{\text {rot }}$ that each firm is allowed to set its price equal to $P_{t}^{\#}$. Taking the limit as $\delta_{\text {rot }}$ goes to one leads to a well-defined relative price level equal to $P^{\#} / P$. We omit this in the text for simplicity but assume it implicitly later when we characterize the steady-state.
} 
where $\varepsilon_{g, t}$ are independently distributed shocks with mean zero and variance $\sigma_{g}^{2}$.

\subsection{Log-Linearizing around the Balanced-Growth Path}

Because technology follows a random walk with drift, output and consumption will inherit the unit root component of technology. To ensure stationarity, we log-linearize the model around the balanced growth path in which $Y / A$ is stationary. Note that equation (1) ensures that $\Lambda_{t} A_{t}$ is also stationary. Defining $y_{t}$ and $\lambda_{t}$ to be the log-deviations of $Y_{t} / A_{t}$ and $\Lambda_{t} A_{t}$ from their balanced growth paths respectively, we can rewrite (1) in log-linearized form as

$$
\left(1-\frac{h}{a}\right)\left(1-\beta \frac{h}{a}\right) \lambda_{t}=\left(1-\frac{h}{a}\right)\left(1-\rho_{g} \beta \frac{h}{a}\right) g_{t}+\frac{h}{a}\left(\beta E_{t} y_{t+1}+y_{t-1}-\varepsilon_{a, t}\right)-\left(1+\beta\left(\frac{h}{a}\right)^{2}\right) y_{t}
$$

and the Euler equation as

$$
\lambda_{t}=E_{t} \lambda_{t+1}+\left(r_{t}-E_{t} \pi_{t+1}\right)
$$

where $\pi_{t} \equiv \log \left(P_{t} / P_{t-1}\right)-\log (\bar{\pi})$ and $\bar{\pi}=P_{t} / P_{t-1}$ along the balanced growth path. The log-deviation of the interest rate $r_{t}$ is defined as $r_{t} \equiv \log \left(R_{t} / \bar{R}\right)$.

We allow the log of steady-state inflation to differ from zero, as in Cogley and Sbordone (2008). The log-deviation of inflation from its steady-state value is a weighted average of sector specific inflation rates

$$
\pi_{t}=\sum_{j} s_{j}{\overline{p^{j}}}^{1-\theta} \pi_{t}^{j}=\sum_{j} s_{j}^{C P I} \pi_{t}^{j} \text { for } j=\{s p, \text { si, rot }, \text { flex }\},
$$

where $\pi_{t}^{j} \equiv \log \left(P_{t}^{j} / P_{t-1}^{j}\right)-\log (\bar{\pi}), \overline{p^{j}} \equiv \overline{P^{j} / P}$ is the steady-state relative price level of sector $j$, and $s_{j}^{C P I} \equiv s_{j}{\overline{p^{j}}}^{1-\theta}$ is the effective share of sector $j$ in the aggregate price index. ${ }^{14}$

Because inflation is not zero on average, sticky-price firms have to take into account the fact that prices will tend to rise on average. Hence, the reset price will generally be greater than the average price level to offset the tendency of prices to rise. From equation (6), we can find the steady-state relative reset price to be

$$
\overline{(B / P)}=\left[\left(1-\gamma_{1}\right) /\left(1-\gamma_{2}\right)\right]^{1 /(1+\omega \theta)} \overline{\left(P^{\#} / P\right)}>\overline{\left(P^{\#} / P\right)},
$$

where $\gamma_{1} \equiv \delta_{s p} a \bar{R}^{-1} \bar{\pi}^{\theta}$ and $\gamma_{2} \equiv \delta_{s p} a \bar{R}^{-1} \bar{\pi}^{1+\theta(1+\omega)}$. But the non-zero rate of inflation also affects the steady-state level of the optimal relative price. Specifically, one can show that

\footnotetext{
${ }^{14}$ Note that equation (12) uses the fact that the weighted sum of the log-linearized relative price levels is zero.
} 


$$
\overline{\left(\frac{P^{\#}}{P}\right)}=\left[s_{1}\left(\frac{1-\delta_{s p}}{1-\delta_{s p} \bar{\pi}^{\theta-1}}\right)\left(\frac{1-\gamma_{1}}{1-\gamma_{2}}\right)^{\frac{(1-\theta)}{(1+\omega \theta)}}+\left(1-s_{1}\right)\right]^{1 /(\theta-1)} .
$$

To the extent that the extra weight attached to $s_{1}$ will in general not be equal to one, the optimal relative price will also then differ from one. We can show the following result:

Proposition 1: When trend inflation is greater than zero, there exists a unique $\beta^{*}\left(\theta, \omega, \delta_{s p}, \bar{\pi}\right)$ such that if $\beta>\beta^{*}$, the steady state average relative price level of sticky price firms is greater than one while the optimal relative price is less than one (and vice versa for $\beta<\beta^{*}$ ).

Proof: See Appendix 1.

When trend inflation is positive, the relative reset price chosen by sticky-price firms declines over time as the aggregate price level rises. If firms care enough about future profits, then they must choose a high reset price today to avoid the relative reset price being too low in the distant future. This will cause the average relative price level of sticky-price firms to be greater than one. However, if firms care primarily about near-term profits ( $\beta$ is small), then firms will choose a reset price that is close to optimal over a short time period. As this relative price declines over time with inflation, the average price level for sticky-price firms will be less than one.

If the steady-state average relative price level of a sector $k$ is greater than one, then its share in the final good will be lower than implied by its mass in the output index. The final goods price index will therefore place a smaller weight on the price of the good of this sector $k$, that is, $s_{k}^{C P I}<s_{k}$. This implies that, upon log-linearizing around steady-state values, price changes in this sector will have a smaller effect on aggregate inflation than would be the case if it had a steady-state relative price of one, as can be seen in equation (12). Because $\beta>\beta^{*}$ in all of our estimates, we have $S_{1}^{C P I}<s_{1}$.

From (4) and the definition of the real marginal cost, the log-linearized deviation of the instantaneously optimal relative price is given by

$$
p_{t}^{\#} \equiv \log \left(P_{t}^{\#} / P_{t}\right)-\log \left(\overline{P^{\#} / P}\right)=(1+\omega \theta)^{-1}\left(\omega y_{t}-\lambda_{t}\right)
$$

To log-linearize the reset price of sticky-price firms, we first rewrite equation (6) in terms of stationary variables 


$$
\sum_{j=0}^{\infty} \delta_{s p}^{j} E_{t}\left\{Q_{t, t+j} \prod_{s=1}^{j}\left(\left(\frac{Y_{t+s}}{Y_{t+s-1}}\right)\left(\frac{P_{t+s}}{P_{t+s-1}}\right)^{\theta}\right)\left[\left(\frac{B_{t}}{P_{t}}\right)^{1+\theta \omega}-\left(\frac{P_{t+j}^{\#}}{P_{t+j}}\right)^{1+\theta \omega} \prod_{s=1}^{j}\left(\frac{P_{t+s}}{P_{t+s-1}}\right)^{1+\theta \omega}\right]\right\}=0
$$

Defining $b_{t}$ as the log deviation of $B_{t} / P_{t}$ from its stationary steady-state value and log-linearizing (14) around the balanced growth path leads to the following expression for the reset price ${ }^{15}$

$b_{t}=\left(1-\gamma_{2}\right) \sum_{j=0}^{\infty} \gamma_{2}^{j} E_{t} p_{t+j}^{\#}+\frac{1}{1+\theta \omega} \sum_{j=1}^{\infty}\left(\gamma_{2}^{j}-\gamma_{1}^{j}\right) E_{t}\left[g y_{t+j}-r_{t+j-1}\right]+\frac{1}{1+\theta \omega} \sum_{j=1}^{\infty}\left[\gamma_{2}^{j}(1+\theta(1+\omega))-\theta \gamma_{1}^{j}\right] E_{t} \pi_{t+j}$,

where $g y_{t} \equiv \log \left(Y_{t} / Y_{t-1}\right)-\log a$ is the (stationary) log-deviation of the growth rate of output from its mean.

Denoting the log-deviation of the relative price level in sector $k$ from its steady state value as $p_{t}^{k} \equiv \log \left(P_{t}^{k} / P_{t}\right)-\log \left(\overline{P_{t}^{k} / P_{t}}\right)$, the log-linearized relative price level of sticky price firms follows

$$
p_{t}^{s p}=\left(1-\delta_{s p}\right){\overline{\left(b / p^{s p}\right.}}^{1-\theta} b_{t}+\delta_{s p} \bar{\pi}^{\theta-1}\left(p_{t-1}^{s p}-\pi_{t}\right),
$$

where the steady-state ratio of reset prices to the sticky-price level is given by ${ }^{16}$

$$
\overline{\left(b / p^{s p}\right)}=\left[\left(1-\delta_{s p}\right) /\left(1-\delta_{s p} \bar{\pi}^{\theta-1}\right)\right]^{1 /(\theta-1)} .
$$

The stationary relative price level for sticky-information firms is given by

$$
\frac{P_{t}^{s i}}{P_{t}}=\left[\left(1-\delta_{s i}\right) \sum_{j=0}^{\infty} \delta_{s i}^{j}\left(\frac{E_{t-j} P_{t}^{\#}}{P_{t}}\right)^{1-\theta}\right]^{1 /(1-\theta)}=\left[\left(1-\delta_{s i}\right) \sum_{j=0}^{\infty} \delta_{s i}^{j}\left(\frac{E_{t-j}\left(P_{t}^{\#} / P_{t}\right)}{\left(E_{t-j} P_{t}\right) / P_{t}}\right)^{1-\theta}\right]^{1 /(1-\theta)},
$$

which yields the following log-linearized expression

$$
p_{t}^{s i}=\left(1-\delta_{s i}\right) \sum_{j=0}^{\infty} \delta_{s i}^{j}\left[E_{t-j} p_{t}^{\#}-C I F E_{j, t}\right],
$$

where the cumulative inflation forecast error is $C I F E_{j, t} \equiv \sum_{s=1}^{j}\left(\pi_{t-j+s}-E_{t-j} \pi_{t-j+s}\right)$. The latter appears because the relative price of sticky information firms depends not only on how firms set prices relative to the expected price level but also on how the expected price level differs from the

\footnotetext{
${ }^{15}$ For these sums to be well-defined in the steady-state requires that $\gamma_{2}<1$. Note that we express the reset price in terms of optimal prices rather than real marginal costs. The reason is that real marginal costs are also a function of the price dispersion $D_{t}$. With non-zero trend inflation, this dispersion term has first order effects. By expressing price setting decisions in terms of desired optimal prices, we reduce the state space of the model by eliminating the need to keep track of the dynamics of price dispersion.

${ }^{16}$ For the relative reset price to be well-defined in equilibrium requires the additional condition that $\delta_{s p} \bar{\pi}^{1-\theta}<1$.
} 
actual price level. To condense the set of expectations we need to keep track of, expression (15) can be rewritten as

$$
p_{t}^{s i}=\delta_{s i} p_{t-1}^{s i}+\left(1-\delta_{s i}\right) p_{t}^{\#}+\left(1-\delta_{s i}\right) \delta_{s i} \sum_{j=0}^{\infty} \delta_{s i}^{j}\left[\left(E_{t-1-j} \pi_{t}-\pi_{t}\right)+E_{t-1-j} \Delta p_{t}^{\#}\right] .
$$

Since the inflation rate for rule-of-thumb firms is

$$
\pi_{t}^{r o t}=\pi_{t-1}
$$

the log-linearized relative price level of rule-of-thumb firms follows

$$
p_{t}^{r o t}=p_{t-1}^{r o t}+\pi_{t-1}-\pi_{t}=p_{t-1}^{r o t}-\Delta \pi_{t} .
$$

Inflation of flexible-price firms is

$$
\pi_{t}^{\text {flex }}=p_{t}^{\#}-p_{t-1}^{\#}+\pi_{t} .
$$

\subsection{Central Bank}

To close the model, we need to describe the central bank's behavior. We follow the literature and assume that the central bank sets interest rates according to a Taylor (1993) type rule with interest smoothing such that

$$
r_{t}=\left(1-\rho_{1}-\rho_{2}\right)\left[\phi_{\pi} \pi_{t}+\phi_{g y} g y_{t}\right]+\rho_{1} r_{t-1}+\rho_{2} r_{t-2}+\varepsilon_{r, t},
$$

which allows the central bank to respond to inflation and the growth rate of output. ${ }^{17}$ The lagged interest rate terms capture the central bank's desire to smooth interest changes. We include two lags of the interest rate in the right-hand side of (20) because in our previous work we document (e.g., Gorodnichenko and Shapiro 2007, Coibion and Gorodnichenko 2008) that two lags appear to be the appropriate statistical description of serial correlation in the policy rule. The policy innovations $\varepsilon_{r, t}$ are assumed to be independently distributed with mean zero and variance $\sigma_{r}^{2}$.

\section{Estimation Approach}

As in Ireland (2004), our log-linearized model has three variables that directly correspond to observable macroeconomic series: the inflation rate, the growth rate of output, and the nominal interest rate. The advantage of focusing on output growth, rather than the output gap as traditionally done, is that output growth is directly observable, whereas the output gap is not. In addition, the

\footnotetext{
${ }^{17}$ We follow Ireland (2004) and allow for the central bank to respond to output growth rather than some measure of the output gap. Our qualitative results are insensitive to the inclusion of an additional output gap term in the Taylor rule, as shown in section 4.4 .
} 
theoretically motivated output gap would tend to be poorly approximated by standard detrending methods (see Andres et al (2005)). ${ }^{18}$ To estimate the underlying parameters of the model, we use a method-of-moments approach that seeks to match the contemporaneous and intertemporal covariances of the observable variables from the data to those of the model. After solving our model for the unique rational expectations equilibrium and letting $\Psi$ denote the vector of parameters in the model, we can rewrite it in reduced form as

$$
X_{t}=A(\Psi) X_{t-1}+B(\Psi) \Phi_{t}+C(\Psi) \Xi_{t},
$$

where $\Phi_{t}$ is the vector of structural shocks, $X_{t}$ is the vector $\left[\begin{array}{llllll}Y_{t}^{\prime} & Q_{t}^{\prime} Y_{t-1}^{\prime} & Q_{t-1}^{\prime} \ldots Y_{t-p}^{\prime} & Q_{t-p}^{\prime}\end{array}\right]^{\prime}$, $Y_{t}=\left[\begin{array}{lll}g y_{t} & \pi_{t} & r_{t}\end{array}\right]^{\prime}$ is the vector of observable variables, $Q_{t}$ is the vector of all unobservable variables, and $\Xi_{t}$ is the vector of serially uncorrelated measurement errors. ${ }^{19}$ The value of $p$ determines the truncation point used for the sticky information sector. Denoting the variance-covariance matrix of the structural and measurement shocks by $\Omega_{\Phi}=\Omega_{\Phi}(\Psi)$ and $\Omega_{\Xi}=\Omega_{\Xi}(\Psi)$, the varianceautocovariance matrix of $X_{t}$ denoted with $\Omega_{X}(\Psi)$ is

$$
\operatorname{vec}\left(\Omega_{X}(\Psi)\right)=[I-A(\Psi) \otimes A(\Psi)]^{-1} \operatorname{vec}\left[B(\Psi) \Omega_{\Phi} B(\Psi)^{\prime}+C(\Psi) \Omega_{\Xi} C(\Psi)^{\prime}\right]
$$

Because measurement errors are assumed to be serially and contemporaneously uncorrelated, $\Omega \Xi$ is a diagonal matrix whose non-zero elements consist of the variances of measurement errors of the growth rate of output $\left(\sigma_{m e, g y}^{2}\right)$, inflation $\left(\sigma_{m e, \pi}^{2}\right)$, and interest rates $\left(\sigma_{m e, r}^{2}\right)$ respectively. The varianceautocovariance matrix for observable variables is then $\Omega_{Y}(\Psi)=\Upsilon \Omega_{X}(\Psi) \Upsilon^{\prime}$ where $\Upsilon$ is the appropriate selection matrix.

On the other hand, we can compute the sample autocovariance matrix for the observed variables, $\Delta_{Y, n} \equiv\left[\operatorname{vech}\left(\hat{\Omega}_{Y, 0}\right)^{\prime} \operatorname{vec}\left(\hat{\Omega}_{Y, 1}\right)^{\prime} \ldots \operatorname{vec}\left(\hat{\Omega}_{Y, n}\right)^{\prime}\right]^{\prime}$ where $\hat{\Omega}_{Y, j}$ is the sample estimate of $\operatorname{cov}\left(Y_{t}, Y_{t-j}\right)$ in the data. We extract the corresponding moments of the model for the observable variables and denote resulting matrix with

\footnotetext{
${ }^{18}$ Gorodnichenko and $\mathrm{Ng}$ (2008) also show that using growth rates of variables could lead to better statistical estimate than using levels of persistent variables.

19 Sargent (1989), Watson (1993) and others emphasize the importance of measurement errors in reported macroeconomic variables as well as in improving the fit of dynamic stochastic general equilibrium models. We introduce measurement errors to absorb those short-term fluctuations in macroeconomic variables that are unrelated to structural shocks.
} 
$\Delta_{Y, n}(\Psi) \equiv\left[\operatorname{vech}\left(\Omega_{Y, 0}(\Psi)\right)^{\prime} \operatorname{vec}\left(\Omega_{Y, 1}(\Psi)\right)^{\prime} \ldots \operatorname{vec}\left(\Omega_{Y, n}(\Psi)\right)^{\prime}\right]^{\prime} . \quad$ In summary, our method of moments estimator of the parameters is then given by

$$
\hat{\Psi}=\arg \min \left\{\left(\Delta_{Y, n}(\Psi)-\Delta_{Y, n}\right)^{\prime} \times W \times\left(\Delta_{Y, n}(\Psi)-\Delta_{Y, n}\right)\right\}
$$

where $W$ is a weighting matrix. The resulting $\hat{\Psi}$ is a consistent estimate, provided that $\hat{\Psi}$ is identified. Following Abowd and Card (1989), Altonji and Segal (1996) and others, we use the identity weighting matrix in the estimation of the covariance structure. ${ }^{20}$ Note that because $\Omega_{Y, n}(\Psi)$ is highly non-linear in $\Psi$, it may be hard to find the global optimum. To address this problem, we use stochastic search optimizers to achieve the global optimum.

Most work on estimating DSGE models relies upon maximum likelihood or Bayesian approaches. We follow our alternative method-of-moments approach for several reasons. First, Ruge-Murcia (2003) compares method of moments estimators with other popular methods such as maximum likelihood for estimating DGSE models and finds that it performs well in simulations. Second, a particularly appealing feature of our method of moments approach is that the moments of the data used in the estimation have an economic interpretation. Comparing the predicted moments of the model to those of the data highlights which features of the data the model can and cannot match. As we discuss in section 4.2.2, our method of moments estimator thus allows us to shed light on why the pure models are rejected in favor of the hybrid model. Thus, we interpret our empirical approach as one way to get inside the "black box" of estimated DSGE models. Finally, we use simulation-based methods to estimate structural parameters without requiring the researcher to take a stand on priors. Our simulation-based method illustrates how medium and large scale models can be estimated within the classical statistical framework.

\section{Results}

We use U.S. data from 1984:Q1 until 2008:Q2. ${ }^{21}$ The growth of output is measured as $400 \times \log \left(R G D P_{t} / R G D P_{t-1}\right)$ where $R G D P$ is chained real gross domestic product. Inflation is measured using the Consumer Price Index by $400 \times \log \left(P_{t} / P_{t-1}\right)$. The interest rate is $400 \times \log \left(1+R_{t}\right)$

\footnotetext{
${ }^{20}$ These authors find that $W$ equal to the identity matrix performs better than the optimal weighting matrix in the context of estimating covariance structures. The optimal weighting matrix, which contains high order moments, tends to correlate with the moments and this correlation undermines the performance of the method of moments estimator. We investigate the robustness of our results to the weighting matrix in section 4.4.

${ }^{21} \mathrm{We}$ focus on this period rather than the full sample because of the structural break in the monetary policy reaction function as well as trend inflation which occurred in the early 1980s.
} 
where $R_{t}$ is the Effective Federal Funds rate (at a quarterly rate). We focus on the contemporaneous covariances and the first three cross-autocovariances of these series to estimate the parameters of the model. We restrict the number of autocovariances to minimize the computational burden and to sharpen inference as the plethora of weakly informative moments tends to deteriorate the estimator's performance. $^{22}$

Our model contains the following set of parameters $\Psi=\left\{a, \bar{R}, \bar{\pi} \beta, \eta, h, \theta, \delta_{s i}, \delta_{s p}, s_{1}, s_{2}, s_{3}\right.$, $\left.\phi_{\pi}, \phi_{g y}, \rho_{1}, \rho_{2}, \rho_{g}, \sigma_{r}, \sigma_{a}, \sigma_{m e, g y}, \sigma_{m e, \pi} \sigma_{m e, r}\right\}$. We calibrate the balanced-growth inflation rate, interest rate, and growth rate of output to those observed in our sample: $\bar{\pi}=1.0077, a=1.0076$, $\bar{R}=1.0130$. Following Ireland (2004), we impose $\beta=0.99$ to guarantee that the consumer's problem is well bounded. We set $\eta=1$, a fairly typical calibrated value for the Frisch labor supply elasticity, and set $\theta=10$, such that the steady-state markup is about $11 \%{ }^{23}$ We experiment with alternative values of $\eta$ and $\theta$ in robustness checks. We choose to calibrate these parameters rather than estimate them because these parameters have known identification problems. For example, Del Negro and Schorfheide (2008) and Canova and Sala (2007) report that standard monetary models have difficulties in distinguishing real (which is governed by $\eta$ and $\theta$ ) and nominal (which is governed by $\delta_{s p}$ and $\delta_{s i}$ ) rigidities. All other parameters are estimated using Markov Chain Monte Carlo (MCMC) methods, with details provided in Appendix 2. We set the truncation of past expectations to $p=12$. We restrict the degree of habit formation, the shares of firms, and the persistence of the preference shock to be between 0 and 1. Price and informational rigidities $\left(\delta_{s p}\right.$ and $\delta_{s i}$ respectively) are restricted to be between 0.3 and $0.95 .^{24}$

\footnotetext{
${ }^{22} \mathrm{We}$ consider the effect of using more moments in the robustness section 4.4.

${ }^{23}$ See Christiano, Eichembaum, and Evans (2005), for example.

${ }^{24}$ The lower bound on pricing and information rigidities is imposed to avoid identification issues, since when these rigidities are low, firms in these sectors behave very much like flexible-price full-information firms, making identification of shares of firms tenuous. In our estimation procedure we also restrict parameters to be consistent with a unique determinate rational expectation equilibrium. To assess whether our results are affected by the boundaries, we estimated a reparameterized version of the model (e.g., instead of drawing $h \in[0,1]$, we drew $\varsigma \in(-\infty . \infty)$ such that $\left.h=\frac{\exp (\varsigma)}{1+\exp (\varsigma)}\right)$ and found very similar results. We also calculated that, for the baseline specification, the MCMC chain generated less than $0.05 \%$ (for the identity weight matrix) and $0.7 \%$ (for the diagonal weight matrix) of draws which led to non-uniqueness/non-existence. Thus, most of our draws were away from the indeterminacy region. In addition, when we ran multiple long ( 2 million draws or more) chains, we observed that the averages across chains converged to very similar values as our baseline estimates (see Appendix Figure A5), which is consistent with the chains exploring the parameter space sufficiently well. Finally, we re-ran chains while fixing close-to-boundary parameters and we found very similar point estimates and standard errors for other parameters.
} 


\subsection{Baseline Estimates}

Table 1 presents our baseline estimates for the hybrid model, as well as estimation results for restricted models. For our baseline model, the degree of habit persistence, at 0.79 , is well within the range of estimates found in other studies. ${ }^{25}$ Our Taylor rule estimates imply strong responses by the central bank to both inflation and the growth rate of output, with substantial inertia apparent in the interest rate. The weight assigned to sticky-price firms is $62 \%$. Sticky-information firms receive a weight of $21 \%$. Both are significantly different from zero. Thus, sticky-prices and stickyinformation jointly account for over $80 \%$ of firms in the model. Rule-of-thumb firms account for $9 \%$ of firms, while flexible price firms receive a share of eight percent. Note that the share of ruleof-thumb firms is not statistically different from zero. If we adjust the shares to reflect the fact that sticky-price firms charge higher prices on average than other sectors, the effective share of stickyprice firms falls to $59 \%$ while the effective share of sticky-information firms rises to $23 \%$. The estimated degree of price rigidity is 0.81 , which implies that sticky-price firms update their prices every five quarters on average. Note that while this is higher than typical estimates of price rigidities (Bils and Klenow (2004) and Nakamura and Steinsson (2007)), the average price duration across all firms is on the order of two to three quarters, which is consistent with the literature. Stickyinformation firms, with an estimated degree of informational rigidity of 0.95 , update their information sets very infrequently, which is consistent with estimated degrees of informational rigidities in Khan and Zhu (2006) and Knotek (2008) over the post-1982 period. In Appendix Figures A1-A5, we provide a variety of diagnostics to verify that our MCMC estimation has converged.

Because no single firm type receives a share of $100 \%$, the first implication of our results is that our nested model best matches the data when more than a single type of firm is present. However, sticky-price and sticky-information firms jointly account for most of the firms in the economy. To assess the relative importance of each type of firm, we consider restricted estimates of our models in Table 1. One version eliminates rule-of-thumb firms. The share of sticky-price firms rises to $63 \%$, while that of sticky-information goes to $23 \%$ of firms. The model achieves only a slightly higher value of the objective function than the baseline case, indicating that rule-of-thumb firms contribute little to the ability of the model to match the data. When one eliminates stickyinformation firms, on the other hand, the model fares worse in matching moments with a $15 \%$

\footnotetext{
${ }^{25}$ See Fuhrer (2000), Grishchenko (2005), and Edge et al (2005).
} 
increase in the value of the objective function. Thus, while rule-of-thumb firms do not appear to play a significant role in matching moments of the data, the sticky-information firms certainly do. Finally, we consider a specification in which both rule-of-thumb and flexible firms are set to zero. This version of the model yields a distribution of firms of about three-quarters sticky-price firms and one-quarter sticky-information firms. This model does almost as well as the baseline model in terms of matching the moments of the data, with only a $2 \%$ increase in the objective function.

Thus, the most striking result from our estimation is that sticky-price and sticky-information firms play the most important role in matching the moments of the data. Once one accounts for these two types of firms, there is little need to allow for rule-of-thumb behavior or flexible-price fullinformation firms. This result is particularly noteworthy for two reasons. First, much of the literature on sticky-prices and sticky-information has focused on testing one model against the other (Korenok (2008), Kiley (2007), Coibion (forthcoming)). Our results imply instead that both are needed to match the moments of the data. Second, sticky-price models are commonly augmented with rule-of-thumb firms to introduce more inflation inertia (e.g., Gali and Gertler (1999)). As we discuss in section 4.3 , in the presence of strategic interaction across sectors rule-of-thumb firms behave similarly to sticky-information firms so that the conventional emphasis on rule-of-thumb firms could have been misplaced. When one allows for both rule-of-thumb and sticky-information firms, the data favors sticky information as a complement to sticky-price models.

\subsection{How Does The Hybrid Model Differ From The Nested Pure Models?}

In this section, we study why the data prefers a hybrid sticky-price sticky-information model over the pure models. To do so, we first re-estimate the structural parameters of the model under the assumption that only one type of firm exists and use these estimates to construct variance decompositions for each model. Second, we compare the predicted moments of the hybrid and pure models to those of the data. Third, we contrast the impulse response functions of each estimated model.

\subsubsection{Estimates of Pure Models}

To get a sense of why the pure models are rejected in favor of a hybrid, we first re-estimate the parameters of the model while imposing that the model be entirely composed of sticky-price, sticky- 
information, or flexible-price full-information firms. ${ }^{26}$ The results are presented in Table 2. Note first that the sticky-price model achieves the lowest value of the objective function after the hybrid model, the sticky-information model comes second, while the flexible-price model does much worse. Across models, the estimated degree of habit formation $(h)$ is fairly high, ranging from 0.69 in the sticky price model to 1.00 in the flexible model. The coefficients of the Taylor rule also differ substantially across models. The sticky-price model points to somewhat stronger responses by the Fed to inflation and output growth than in the hybrid model while the sticky information model yields a much larger response to output growth but a smaller response to inflation. The estimated degrees of price and informational rigidities are close to those in the hybrid model. Turning to estimated shock processes, there are important differences in the size of the shocks across models. For the sticky-price model and the flexible model, the volatility of interest rate shocks is not significantly different from zero. For the sticky-information model, the standard deviation of technology shocks is much lower than in the hybrid model and insignificantly different from zero. Measurement errors for estimated sticky-price and sticky-information models are of the same order of magnitude as in the hybrid model. For the flexible model, on the other hand, measurement error for the interest rate is much higher than previously found.

These differences across models have important implications for the relative importance attributed to each shock in explaining macroeconomic dynamics. Table 3 presents the one-year ahead variance decompositions of output growth, inflation, and interest rates due to structural shocks in each model. ${ }^{27}$ For output growth, all of the models yield the conclusion that most of the variance is due to preference shocks. Note however that the second most important shock is the policy shock in the sticky-information model and the technology shock in all other models. For inflation, there is much more variation across models. The hybrid model attributes much of the variance of inflation to technology and preference shocks. The sticky-price model yields a similar decomposition. The sticky-information and flexible models, on the other hand, both attribute much more importance to

\footnotetext{
${ }^{26}$ Because the dynamic responses of each pure model are so different from each other across shocks, as well as the fact that all the parameters of the model are estimated jointly, it is misleading to take our estimated values and simply consider imposing that the model only consist of one type of firm to determine how each model fares independently.

${ }^{27}$ The share of variance attributed to measurement error is $51 \%, 68 \%$, and $0.2 \%$ for output growth rate, inflation rate, and interest rate respectively. Although the measurement errors soak up a relatively large fraction of contemporaneous variation, they have no effect on (auto)covariances which the model can match well. The main reason why we have to rely on measurement errors is because there is a clear break in the size of the autocovariances of output growth rate and inflation rate. Any standard model we experimented with could not simultaneously generate the large variance and (relatively) low autocovariances. The measurement error for the interest rate is not as large as it is for other variables because the autocovariances are close in magnitude to the variance.
} 
monetary policy innovations. With respect to interest rate fluctuations, all of the models attribute much of the variation to preference shocks, although the sticky information model again attributes some role $(25 \%)$ to monetary policy innovations while the flexible model assigns a sizable weight to technology shocks. Thus, overall, the sticky-price model yields a variance decomposition of macroeconomic variables that closely mirrors that of the hybrid model, with preference shocks being most important but with technology shocks playing a key role in explaining inflation. The stickyinformation model places little weight on technology shocks, and instead assigns a much larger role to monetary policy innovations.

\subsubsection{Comparing Predicted Moments}

To further contrast the pure and hybrid models, we consider which features of the data each model can match. Figure 1 presents the autocovariances of the observable variables implied by the models and those found in the data, as well as 95\% confidence intervals derived from a non-parametric bootstrap. $^{28}$ First and most dramatically, the flexible price model is unable to reproduce the high autocovariance of interest rates and output growth rate observed in the data. Second, all other models perform adequately at reproducing the autocorrelation of output growth and interest rates, largely because this is driven by the estimates of internal habit formation and high interest rate smoothing in the central bank's reaction function. Third, the sticky-information model tends to somewhat overstate the persistence of inflation.

Figure 2 presents the cross-covariances of inflation with respect to leads and lags of output growth and interest rates, as well as that of output growth to leads and lags of interest rates. The moments of the data indicate that inflation leads output growth and interest rates, such that high inflation today is associated with higher interest rates and lower output growth in subsequent quarters. In addition, output growth leads interest rates. The fully flexible model is largely incapable of reproducing these lead-lag characteristics of the data. The sticky-information model has difficulty reproducing the fact that inflation leads output growth and interest rates: in the case of output growth, the sticky-information model predicts that the highest covariance (in absolute value) is contemporaneous while in the case of interest rates, the sticky-information model predicts that inflation should lag interest rates. The sticky-price model, on the other hand, replicates these lead-

\footnotetext{
${ }^{28}$ The boostrap is done by running a VAR(4) on our measures of GDP growth, inflation, and interest rates over the same time period as our sample. We then use the VAR to simulate new data of the same length and calculate the auto and cross covariances from the simulated data. We use 2000 bootstraps to generate the $95 \%$ confidence interval.
} 
lag patterns more precisely. This reflects the forward-looking behavior embodied in the reset-price decisions of sticky-price firms. The hybrid model, overall, yields dynamics that are very similar to the sticky-price model.

\subsubsection{Impulse Responses}

To understand why the sticky-information model places more weight on monetary policy shocks but less weight on technology than either the hybrid or pure sticky-price model, it is helpful to consider the impulse responses of the observable variables to each shock from the different models. These are presented in Figure 4 for the hybrid, sticky-price and sticky-information models. ${ }^{29}$ In each case, we use the estimated parameters from each model, presented in Table 2, to derive impulse responses to one-unit shocks.

Consider first the effects of preference shocks, since these shocks account for the brunt of the variance decomposition of macroeconomic variables across models. In response to preference shocks, output growth jumps up and returns monotonically back to zero over time. This response is similar across models and is driven by the estimated habit formation parameter and the persistence of the shock. The rapid decline in output growth helps match the autocorrelation function of output growth for all models. In addition, the interest rate rises in response to the positive output growth, but does so in a hump-shaped manner, reflecting the strong degree of interest smoothing. This gradual increase in the interest rate helps replicate the observation that output growth leads interest rates in the data. Because inflation is positive after this shock (albeit with a lag for stickyinformation), this shock can also help replicate the positive correlation between inflation and interest rates observed in the data. However, it cannot explain the contemporaneous negative correlation between inflation and output growth. For the sticky-information model, the delayed response of inflation to the preference shock causes inflation to lag output growth and interest rates, a result at odds with the data.

Turning to technology shocks, the key finding for sticky price and hybrid models are the contemporaneous decrease in inflation and increase in output growth. This response allows these two models to replicate the unconditional negative correlation between inflation and output growth observed in the data. In addition, because inflation jumps down on impact and returns rapidly to the

\footnotetext{
${ }^{29} \mathrm{We}$ omit responses from the flexible price model because a) flexible price and rule-of-thumb firms account for a small fraction of firms in the hybrid model and b) the responses of flexible firms are very large on impact and dwarf those of the other models.
} 
steady-state while output growth converges only slowly after this permanent shock, this shock allows the sticky-price and hybrid models to replicate the finding that inflation leads output growth. This accounts for the substantial weight assigned to this shock by the sticky-price and hybrid models in accounting for inflation dynamics. For the sticky-information model, the permanent nature of the technology shock yields a very delayed response of inflation, which again tends to counterfactually imply that inflation lags output growth.

In response to monetary policy shocks, the increase in the interest rate leads to a decrease in output growth and inflation across models. Since this tends to imply a negative correlation between output growth and interest rates, as well as between inflation and interest rates, the sticky-price and hybrid models assign almost no weight to this shock, as the key lead-lag relationships are already accounted for by the preference and technology shocks. However, we can see from this impulse response why monetary policy shocks play such an important role for the sticky-information model. Note that inflation declines for a number of quarters after a monetary policy shock under the stickyinformation model, a point emphasized by Mankiw and Reis (2002). The interest rate, on the other hand, peaks in the second quarter then returns monotonically back to zero. Thus, after the first period, the correlation between inflation and the interest rate is positive in the sticky information model as inflation and interest rates decline simultaneously. In addition, because inflation falls in the first period while the interest rate only starts to decline in the second period, this shock helps deliver a lead of inflation over interest rates, which was the feature of the data that the stickyinformation model could not match with preference and policy shocks. Thus, the sticky-information model places much more weight on monetary policy shocks than either the sticky-price or hybrid models.

\subsection{How Important Is Strategic Interaction Among Different Price-Setting Firms?}

One question that naturally arises with hybrid models is how the behavior of firms within the hybrid model compares to their behavior when they are the only type of firm. For this purpose, Figure 4 plots the response of inflation in each sector to each shock, as well as the response of aggregate inflation in a model consisting only of this type of firm. For the latter, we use the estimated 
parameters of the hybrid model and simply alter the share of firms to isolate the strategic interaction effect. $^{30}$

Focusing first on sticky-price firms, in response to monetary policy, technology, and preference shocks, inflation among sticky-price firms within a hybrid model is substantially dampened (by about $30 \%$ on impact) relative to what it would have been had these been the only type of firm in the model. For sticky-information firms, the effect is reversed: their inflation response is more rapid within the hybrid model than in a pure sticky-information model. This is strategic complementarity at work: the resulting inflation responses in each sector are much more similar than the inflation responses of the pure models. The effect of strategic complementarity is even more striking in the case of flexible-price full-information firms. Whereas inflation for these firms would be substantial on impact—-but virtually nil in subsequent periods-within the hybrid model their inflation response is severely dampened. This reflects how much more sensitive these firms are to the behavior of other firms because they are unconstrained in their actions whereas all other firms face some kind of constraint, which is similar in spirit to Haltiwanger and Waldman (1991).

In the bottom row of Figure 4 we contrast the dynamics of aggregate inflation in the hybrid model and the dynamics of the weighted average of inflation in the pure models. We interpret the weighted average dynamics as a case where consumers have a two-tier utility function with very low elasticity of substitution across sectors and $\theta=10$ elasticity of substitution within sectors. ${ }^{31}$ The hybrid model exhibits more gradual and persistent dynamics than the weighted average over pure models thus suggesting that ignoring strategic interaction between firms with different price setting may considerably distort the aggregate dynamics. Figure 4 also illustrates why previous work could readily have mistaken sticky-information firms for rule-of-thumb firms. The behavior of stickyinformation firms within the hybrid model is quite similar to that of rule-of-thumb firms. Both display delayed responses of inflation to shocks and serve to dampen the response of aggregate

\footnotetext{
${ }^{30}$ With policy responding to endogenous variables, the behavior of firms in pure models should differ from the hybrid model even in the absence of pricing complementarities. We are grateful to an anonymous referee for pointing this out. To address this issue, we considered a version of the model with exogenous money supply and a money demand curve. The results were almost identical to those reported in the paper so we can argue that the dynamics in Figure 4 are driven largely by strategic complementarity in price setting rather than by the endogenous response of monetary policy-makers.

${ }^{31}$ In other words, production in the economy is split into four islands, each of which is populated with a single-type of price setting firms, there is no direct interaction across islands, aggregate behavior is a (weighted) sum of dynamics across islands and then we compare these aggregate dynamics with the dynamics in the hybrid model when different types of firms are allowed to interact.
} 
inflation in the model. However, sticky-information firms adjust prices more gradually than rule-ofthumb firms and, according to our empirical results, the data clearly favor sticky information over rule-of-thumb firms within the hybrid model as complements to sticky-price firms.

\subsection{Robustness Analysis}

In this section, we consider the robustness of our estimates to several potential issues. First, we consider the use of a larger set of moments in the estimation. Second, we discuss the use of a nonidentity weighting matrix in the estimation. Third, we change the labor supply elasticity to correspond to indivisible labor. Fourth, we relax the Taylor rule to allow for the central bank to respond to the output gap. Fifth, we reproduce our estimates using only AR(1) interest smoothing in the central bank's reaction function. ${ }^{32}$ Sixth, we consider alternative values for the elasticity of substitution in intermediate goods.

The first issue we address is the set of moments used in the estimation. Our baseline results relied on the autocorrelations of our observable variables over three quarters and dynamic crosscorrelations at maximum leads and lags of three quarters as well. The purpose of focusing on such a restricted set of moments was to concentrate on those moments that are most precisely estimated. As a robustness check, we consider the use of a larger set of moments, specifically using autocovariances over two years, and report results in Table 4. Most of the parameters are similar to baseline estimates. The estimated levels of price and informational rigidities are almost identical to our baseline estimates and the estimated shares of firms continue to imply that more than $80 \%$ of firms are sticky-price or sticky-information firms.

An alternative approach to dealing with the precision of the moments used in the estimation is to allow for a non-identity weighting matrix. Although the optimal weighting matrix would seem an ideal candidate, many studies report poor performance of this weighting matrix in applications (e.g., Boivin and Giannoni 2006) and Monte Carlo simulations (e.g., Altonji and Segal (1996)) that involve estimation of covariance structures. ${ }^{33}$ A practical compromise is a diagonal weighting matrix with estimated variances of the moments on the diagonal and zeros for off-diagonal entries. Replicating our baseline estimation procedure with the diagonal weighting matrix, we find that

\footnotetext{
${ }^{32}$ All robustness checks are done by using the same starting values and estimation approach as the baseline estimation.

${ }^{33}$ We ran Monte Carlo simulations of our model and found that the identity weighting matrix outperformed the diagonal weighting matrix and the optimal weighting matrix in time series of the same length as ours. These results are available upon request.
} 
sticky-price firms account for approximately fifty percent of firms (but we cannot reject equality to the baseline estimate of sixty percent), while rule-of-thumb and sticky-information firms account for $18 \%$ and $16 \%$ respectively. Neither of these estimates is statistically different from zero or statistically different from our original estimates. Essentially, the use of the diagonal weight matrix downplays some informative moments and does not allow us to clearly separate rule-of-thumb and sticky-information firms. Most other parameter estimates are broadly similar to the estimates based on the identity weight matrix.

We also consider sensitivity to the elasticity of labor supply. While most empirical work has found low elasticities of labor supply, some of the RBC literature has focused on the case with infinite labor supply (as in Hansen (1985)). In Table 4, we present estimates of the hybrid model under the assumption of indivisible labor $(\eta=\infty)$, which implies that $\omega=0$ so that there is no strategic complementarity in price setting. Eliminating strategic complementary has a dramatic effect on the results. Specifically, the shares of sticky-information and flexible price firms both go to zero, while that of rule-of-thumb firms rises to $50 \%$. This change in outcome leads to a substantial deterioration in the model's ability to match the data: the objective function rises by over $40 \%$. The reduced share of sticky-information firms reflects the fact that, in the absence of strategic complementarity in price setting, sticky-information firms fail to produce inflation inertia. Because sticky-price firms tend to induce excessive forward-looking behavior in inflation, the model needs other types of firms to slow down the adjustment of inflation to shocks. With sticky-information firms unable to achieve this role in the absence of strategic complementarity, the estimation instead places a significant weight on rule-of-thumb firms.

Another robustness issue that we consider is allowing for the central bank to respond to the output gap. While this is often included in Taylor rules, our baseline approach instead includes only output growth. This is because output growth is directly observable to the central bank, whereas the gap is not. In addition, Ireland (2004) and Coibion and Gorodnichenko (2008) find little evidence of a response to the gap since the early 1980s once output growth is included in the Taylor rule. As a robustness check, we consider the following Taylor rule $r_{t}=\left(1-\rho_{1}-\rho_{2}\right)\left[\phi_{\pi} \pi_{t}+\phi_{g y} g y_{t}+\phi_{x} x_{t}\right]+\rho_{1} r_{t-1}+\rho_{2} r_{t-2}+\varepsilon_{r, t}$ where $x$ is the log-deviation between actual output and the level of output that would occur in the absence of price and informational rigidities. The estimated response to the output gap is very low and not statistically different from zero while the other parameters are largely unchanged. 
We also consider another robustness check with respect to the central bank's reaction function. Specifically, we integrate the following Taylor rule into our model $r_{t}=\left(1-\rho_{1}\right)\left[\phi_{\pi} \pi_{t}+\phi_{g y} g y_{t}\right]+\rho_{1} r_{t-1}+\varepsilon_{r, t}$ which restricts interest smoothing to be an $\operatorname{AR}(1)$ process. While much of the literature focuses on this specification, recent empirical evidence on the Fed's reaction function has found an AR(2) specification to be preferable (see Blinder and Reis (2005) and Coibion and Gorodnichenko (2008)). The estimated results using the AR(1) specification are presented in Table 4 . The results are broadly unchanged, with sticky-price firms accounting for $60 \%$ of firms and sticky-information firms accounting for $15 \%$. The share of flexible-price firms rises to $16 \%$. However, imposing an AR(1) specification reduces the ability of the model to match the moments of the data, and the objective function rises by over $10 \%$ relative to our baseline estimates.

Our final robustness check is with respect to the elasticity of substitution across intermediate goods $\theta$. We fixed this parameter in our baseline estimation because previous work has shown that it is difficult to differentiate empirically between nominal and real rigidities, making the joint identification of $\theta$ and the shares of firms tenuous. To assess how sensitive our results are to $\theta$, we redid our baseline estimation procedure for values of $\theta$ ranging from 7 to 15 . Our results for the key parameters of interest, shares of firms and the degree of price and information rigidities, are in Figure 5. In Panel A, we can see that lower values of $\theta$ have a substantial effect on estimated shares of firms. Specifically, the share of sticky-information firms declines rapidly while that of stickyprice firms rises. As lower values of $\theta$ reduce strategic complementarity in price setting, we get higher estimates of price rigidity to keep the persistence of inflation high (Panel B). However, the fit of the model worsens substantially as strategic complementarity decreases moderately (Panel C). With higher values of $\theta$, on the other hand, the estimated shares of firms are very similar to our baseline estimates under the assumption of $\theta=10$. As $\theta$ rises, the degree of strategic complementarity increases, as does the inherent persistence of inflation, so this leads to lower estimates of price rigidity. The fit of the model actually improves with higher values of $\theta$, indicating that even more strategic complementarity is desirable to match the data. Thus, one could interpret our baseline results as a lower bound on the importance of strategic complementarity in price setting across heterogeneous price-setting firms. 


\section{Implications for Optimal Monetary Policy}

The presence of different types of firms in the model raises the issue of what kind of monetary policy is optimal in such a setting. To assess the effect of different policies, we follow much of the literature and assume that the central banker has the following loss function

$$
L_{1}=\operatorname{var}\left(\pi_{t}\right)+\omega_{y} \operatorname{var}\left(x_{t}\right)+\omega_{r} \operatorname{var}\left(r_{t}\right),
$$

where $\omega_{y}$ and $\omega_{r}$ show the weight on output gap and interest rate volatility relative to inflation volatility so that the variability in the output gap (and later the output growth rate) and the interest rate are converted to their inflation-variance equivalents. We also consider an alternative loss function which penalizes the volatility of output growth instead of the volatility of the output gap:

$$
L_{2}=\operatorname{var}\left(\pi_{t}\right)+\omega_{y} \operatorname{var}\left(g y_{t}\right)+\omega_{r} \operatorname{var}\left(r_{t}\right),
$$

This alternative loss function may be interesting for our analysis because, as Amato and Laubach (2004) show, habit formation introduces a concern for the volatility in the change of consumption and, hence, the loss function should include a term that captures the volatility of output growth.

In principle, parameter $\omega_{y}$ can be derived from the Phillips curve. However, because we have different interacting price-setting mechanisms as well as non-zero steady state inflation, we could not find a closed-form solution for the Phillips curve and $\omega_{y}$ and so objective functions (21) and (22) are not necessarily model consistent for welfare calculations. Consequently, we are agnostic about the relative weight of output gap variability and we experiment with different values of $\omega_{y}$. In the baseline scenario, we set $\omega_{y}=1$. The last term in the loss function is the penalty for the volatility of the policy instrument (interest rate). Having $\omega_{r}$ greater than zero helps to keep the optimal responses to output growth and inflation bounded. We follow Woodford (2003) and calibrate $\omega_{r}=0.077$.

We constrain our analysis to simple rules similar to the estimated interest rate rule (20) for reasons highlighted in Williams (2003). First, simple rules can often closely approximate fully optimal rules. Second, simple rules tend to be more robust. Third, with many sectors and complicated structure of the model, we could not find a closed form solution of the objective function and hence could not derive fully optimal rules.

The first question we pose is whether the central bank could have achieved lower losses by responding differently to aggregate inflation and output growth than what is implied by our estimates of the Taylor rule. Panel A in Figure 6 presents the isoloss maps for different combinations of $\phi_{\pi}$ 
and $\phi_{g y}$ in the Taylor rule. ${ }^{34}$ Generally, there are substantial gains from increasing the response to inflation which reduces the volatility of inflation, the interest rate and the output gap. Holding everything else constant, a more aggressive response to inflation decreases the volatility of inflation, the interest rate, and the output gap and weakly increases the volatility of output growth (see Appendix Figure A6). In contrast, a stronger response to the output growth rate has the opposite effect on the volatility of relevant macroeconomic variables. Since the volatility of output growth is fairly insensitive to changes in $\phi_{\pi}$ and $\phi_{g y}$ in the Taylor rule, social welfare generally improves with larger $\phi_{\pi}$ and somewhat smaller $\phi_{g y}$ irrespective of what values we use for $\omega_{y}$ in the loss functions (see Appendix Figure A9).

The second question we ask is whether the optimal policies in pure sticky-price and stickyinformation models are similar to those found in the hybrid model. In particular, one may be concerned that using pure models to design policy rules can misguide the policymaker about his or her tradeoffs. Because scales of the social loss maps vary across models, we compute isoloss maps for pure sticky price (PSP) and pure sticky information (PSI) models and normalize these maps by the corresponding values of the loss function evaluated at the estimated Taylor rule parameters. These rescaled isoloss maps, which we call relative welfare maps, can be interpreted as losses relative to the loss incurred when the policymaker uses the estimated Taylor rule. We also scale the isoloss map for the hybrid model and then divide the relative welfare for the PSP and PSI models by the relative welfare map for the hybrid model. In summary, we consider maps

$$
\left[\frac{L_{k}^{P S P}\left(\phi_{\pi}, \phi_{g y}\right) / L_{k}^{P S P}\left(\hat{\phi}_{\pi}, \hat{\phi}_{g y}\right)}{L_{k}^{H Y B R}\left(\phi_{\pi}, \phi_{g y}\right) / L_{k}^{H Y B R}\left(\hat{\phi}_{\pi}, \hat{\phi}_{g y}\right)}\right] \text { and }\left[\frac{L_{k}^{P S I}\left(\phi_{\pi}, \phi_{g y}\right) / L_{k}^{P S I}\left(\hat{\phi}_{\pi}, \hat{\phi}_{g y}\right)}{L_{k}^{H Y B R}\left(\phi_{\pi}, \phi_{g y}\right) / L_{k}^{H Y B R}\left(\hat{\phi}_{\pi}, \hat{\phi}_{g y}\right)}\right], k=1,2 \text {, }
$$

where $\left(\hat{\phi}_{\pi}, \hat{\phi}_{g y}\right)$ are estimated values of the policy reaction function reported in Table 1.

The resulting maps (23) show to what extent using PSP and PSI models misinforms the policymaker about tradeoffs relative to the hybrid model. ${ }^{35}$ Specifically, if the ratio of relative welfare maps for PSP or PSI to the relative welfare map for the hybrid model is close to one uniformly in $\left(\phi_{\pi}, \phi_{g y}\right)$ space, there is no distortion in the tradeoffs. If the ratio is greater than one (smaller than one) with deviations of $\left(\phi_{\pi}, \phi_{g y}\right)$ from $\left(\hat{\phi}_{\pi}, \hat{\phi}_{g y}\right)$, then using the PSP or PSI model

\footnotetext{
${ }^{34}$ In this and subsequent exercises, we hold the interest rate smoothing parameters of the Taylor rule fixed at their estimated values.

${ }^{35}$ Alternatively, one can interpret the ratio of the relative welfare maps as the difference-in-difference estimator for the changes in the welfare changes when the policymaker considers alternative values of $\phi_{\pi}$ and $\phi_{g y}$ in the Taylor rule.
} 
understates (overstates) the gain in welfare. Panels B and C in Figure 6 show the ratio of relative welfare maps (23) for PSP and PSI models respectively. These maps demonstrate that using pure models instead of the hybrid model can greatly mislead the policymaker about potential gains from using alternative policy rules. For example, when the policymaker uses the PSI model to design policy, he or she underestimates the benefits from stronger responses to inflation relative to gains implied by the hybrid model because the ratio of relative welfare maps rapidly falls as $\phi_{\pi}$ increases. Hence, we conclude that using pure models can provide a distorted picture of tradeoffs actually faced when price-setting is heterogeneous.

Given that PSP and PSI models have different implications for whether the central bank should target the price level or inflation, the third question we ask is whether our hybrid model predicts an important role for price level targeting. To answer this, we augment the Taylor rule with a term that corresponds to price level targeting (PLT):

$$
r_{t}=\left(1-\rho_{1, r}-\rho_{2, r}\right) \phi_{\pi} \pi_{t}+\left(1-\rho_{1, r}-\rho_{2, r}\right) \phi_{P L T} p_{t}+\left(1-\rho_{1, r}-\rho_{2, r}\right) \phi_{g y} g y_{t}+\rho_{1, r} r_{t-1}+\rho_{2, r} r_{t-2}+\varepsilon_{r, t},
$$

where $p_{t}$ is the price level linearized around $p_{t}^{*}=p_{0} \bar{\pi}^{t}$. In this exercise, we fix $\phi_{g y}$ at the estimated value, vary $\phi_{\pi}$ and $\phi_{P L T}$ and plot the resulting isoloss amps in Panel D of Figure 6 and the associated volatilities of the growth rate of output, the output gap, inflation and the interest rate in Appendix Figure A7. In general, there are significant welfare gains from having an element of PLT in the Taylor rule. In fact, even small positive responses to deviations from the price level target dramatically reduce the volatility of the output gap, the interest rate and inflation. At the same time, similar to the inflation response, a more aggressive PLT response tends to weakly increase the volatility of output growth. However, because this increase is very small, the changes in welfare are strongly dominated by declines in $\operatorname{var}\left(x_{t}\right), \operatorname{var}\left(\pi_{t}\right)$, and $\operatorname{var}\left(i_{t}\right)$ so that PLT is generally desirable for all reasonable values of $\omega_{y}$ (see Appendix Figure A7). Importantly, introducing PLT in the policy reaction function eliminates a region of equilibrium indeterminacy (compare with Panel A, Figure 6) and therefore PLT could be useful in ways other than reducing the volatility of macroeconomic variables.

Finally, having the central bank respond to aggregate inflation imposes the restriction that a one percent increase in inflation in a sector leads to an increase in the interest rate proportional to that sector's effective share of inflation dynamics, as defined in equation (20). The fourth question 
we ask is whether there are gains to be had by responding differently to inflation in each sector. For this purpose, we compute optimal policy rules using

$$
\begin{aligned}
r_{t}= & \left(1-\rho_{1, r}-\rho_{2, r}\right) \phi_{\pi}^{(S P)} \pi_{t}^{(S P)}+\left(1-\rho_{1, r}-\rho_{2, r}\right) \phi_{\pi}^{(S I+R O T+F L E X)} \pi_{t}^{(S I+R O T+F L E X)} \\
& +\left(1-\rho_{1, r}-\rho_{2, r}\right) \phi_{g y} g y_{t}+\rho_{1, r} r_{t-1}+\rho_{2, r} r_{t-2}+\varepsilon_{r, t}
\end{aligned}
$$

where we assume that the central banker can differentiate between sectors that have prices fixed for some time $(S P)$ and those that have prices changing every period (SI, ROT and FLEX). Here, we again fix $\phi_{g y}$ at the estimated value, vary $\phi_{\pi}^{(S P)}$ and $\phi_{\pi}^{(S I+R O T+F L E X)}$ and plot the resulting isoloss maps in Panel E of Figure 6 and associated volatilities of the growth rate of output, the output gap, inflation and the interest rate in Appendix Figure A8. ${ }^{36}$ We find a striking result: the isoloss maps are approximately linear in $\phi_{\pi}^{(S P)}$ and $\phi_{\pi}^{(S I+R O T+F L E X)}$ in the neighborhood of the estimated response to inflation. Hence, the policymaker does not face an increasing marginal penalty for targeting only one of the sectors. In addition, we find that only responding to inflation in the sticky-price sector is generally more stabilizing than only responding to inflation in the other sectors, which is consistent with Aoki (2001) and with the notion that sticky-price firms play a disproportionally large role in governing inflation dynamics through strategic complementarity in pricing setting, as demonstrated in section 4.3. At the same time, the policymaker can generally achieve a lower level of social loss by having a less aggressive response to inflation when he or she targets inflation in all sectors rather than in just one sector. Although the slope of the isoloss curves is not equal to one and hence there is a possibility to improve welfare by making the response to inflation more aggressive in one sector and less aggressive in another sector, the gains from the differentiated response to sector-specific inflation appear to be rather small.

\section{Conclusion}

Empirical work has documented a striking amount of heterogeneity in pricing practices: both in the frequency at which firms update prices as well as in the source of costs underlying firm decisionmaking processes. We present a model in which four commonly used representations of how firms set prices are allowed to coexist and interact via their price-setting decisions. This model nests many specifications previously considered in the literature. We find that the two most important types of price-setting behavior are described by sticky prices and sticky information while rule-of-thumb and

\footnotetext{
${ }^{36}$ Note that moving along the $45^{\circ}$ line in Panel E corresponds to moving along the vertical line that passes the estimated Taylor rule parameter combination in Panel A.
} 
flexible pricing are quantitatively unimportant. This finding suggests that sticky-information firms may be more important than previously thought.

In addition, because the dynamic cross-covariances reveal important insights about the leadlag structure of economic relationships, we can provide intuitive explanations for how the hybrid model outperforms pure sticky-price or sticky-information models. For example, we argue that a pure sticky information model tends to under-predict the degree of forward-looking behavior in inflation. In contrast, previous work that emphasized the time series representation of the data could not readily provide an economic rationale for why one model is preferred to others.

Heterogeneity in price-setting poses important issues for policymakers. We demonstrate that focusing on models with a single price-setting mechanism can misinform central bankers about trade-offs they face. Our simulations suggest that a more aggressive response to inflation, which may include an element of price level targeting, could substantially improve social welfare functions. At the same time, we do not find large benefits from targeting sectors with some particular form of price setting so that targeting aggregate inflation is a reasonable strategy for policymakers.

While we focus on the possibility of important differences in how firms set prices, this approach could be naturally extended to wage-setting decisions. Christiano, Eichembaum and Evans (2005), for example, argue that sticky wages with indexation are a particularly important element in matching macroeconomic dynamics. Yet, as with prices, allowing for indexation cannot reproduce the fact that wages often do not change for extended periods of time. A more natural approach could be to allow for heterogeneity in wage-setting assumptions for different sectors of the economy. This would capture the fact that some sectors have highly flexible wages, others have sticky wages without indexation, and some sectors, particularly those under union contracts, choose time paths for future wages infrequently. Even with relatively small sticky-wage or union-wage sectors, the behavior of the flexible-wage sector could be substantially altered if there is strategic complementarity in wage-setting decisions. 


\section{References}

Abowd, John M. and David Card. 1989. "On the Covariance Structure of Earnings and Hours Changes," Econometrica 57(2), 411-445.

Altonji, Joseph G., and Lewis G. Segal, 1996. "Small-sample bias in GMM estimation of covariance structures," Journal of Business and Economic Statistics 14(3), 353 -366.

Amato, J.D., and T. Laubach, 2004. "Implications of habit formation for optimal monetary policy," Journal of Monetary Economics 51(2), 305-325.

Andres, Javier, David Lopez-Salido, and Edward Nelson. 2005. "Sticky-Price Models and the Natural Rate Hypothesis," Journal of Monetary Economics 52(5), 1025-1053.

Ascari, Guido. 2004. "Staggered Prices and Trend Inflation: Some Nuisances," Review of Economic Dynamics 7, 642-667.

Aoki, Kosuki. 2001. “Optimal Monetary Policy Responses to Relative-Price Changes," Journal of Monetary Economics 48, 55-80.

Ascari, Guido and Tiziano Ropele. 2005. "Trend Inflation, Taylor Principle, and Indeterminacy." Manuscript.

Ball, Laurence, N. Gregory Mankiw, and Ricardo Reis. 2005. "Monetary Policy for Inattentive Economies," Journal of Monetary Economics 52(4), 703-725.

Barsky, Robert and Lutz Killian. 2001. "Do We Really Know that Oil Caused the Great Stagflation? A Monetary Alternative," in B. Bernanke and K. Rogoff (eds.), NBER Macroeconomics Annual 2001, May 2002, 137-183.

Bils, Mark and Peter Klenow. 2004. "Some Evidence on Importance of Sticky-Prices," Journal of Political Economy 112, 947-985.

Blinder, Alan S. and Ricardo Reis, 2005. "Understanding the Greenspan Standard," published in The Greenspan Era: Lessons for the Future, Jackson Hole: Federal Reserve Bank of Kansas City, 11-96.

Bouakez, Hafed, Emanuela Cardia and Francisco Ruge-Murcia. 2006. "The Transmission of Monetary Policy in a Multi-Sector Economy." Manuscript.

Boivin, Jean and Marc Giannoni, 2006, "Has Monetary Policy Become More Effective?" Review of Economics and Statistics, 88(3), 445-462.

Calvo, Guillermo A. 1983. "Staggered Prices in a Utility-Maximizing Framework," Journal of Monetary Economic 12, 383-398.

Canova, Fabio, and Luca Sala. 2007. "Back to square one: identification issues in DSGE models," manuscript.

Carvalho, Carlos Viana de. 2006. "Heterogeneity in Price Setting and the Real Effects of Monetary Shocks," Frontiers of Macroeconomics: Vol. 2 : Iss. 1, Article 1.

Chernozhukov, Victor and Han Hong. 2003. "An MCMC Approach to Classical Estimation," Journal of Econometrics 115(2), 293-346.

Christiano, Lawrence, Martin Eichenbaum, and Charles Evans. 2005. "Nominal Rigidities and the Dynamic Effects of a Shock to Monetary Policy," Journal of Political Economy 113(1), 1-45.

Clarida, Richard, Jordi Gali, and Mark Gertler. 2000. "Monetary Policy Rules and Macroeconomic Stability: Evidence and Some Theory," Quarterly Journal of Economics 155(1), 147-180.

Cogley, Timothy and Argia M. Sbordone. 2008. "Trend Inflation, Indexation, and Inflation Persistence in the New Keynesian Phillips Curve," forthcoming in American Economic Review.

Coibion, Olivier, 2006. "Inflation Inertia in Sticky-Information Models," BE Journals: Contributions to Macroeconomics 6(1), Article 1.

Coibion, Olivier. "Testing the Sticky Information Phillips Curve," forthcoming in The Review of Economics and Statistics. 
Coibion, Olivier and Yuriy Gorodnichenko, 2008. "Monetary Policy, Trend Inflation and the Great Moderation: An Alternative Interpretation." Manuscript.

Del Negro, Marco, and Frank Schorfheide. 2008. "Forming priors for DSGE models (and how it affects the assessment of nominal rigidities)," Journal of Monetary Economic 55(7), 11911208.

Dhyne, Emmanuel, Luis J. Alvarez, Herve Le-Bihan, Giovanni Veronese, Daniel Dias, Johannes Hoffmann, Nicole Jonker, Patrick Lunnemann, Fabio Rumler, and Jouko Vilmunen. 2005. "Price setting in the euro area: some stylized facts from individual consumer price data," European Central Bank, Working Paper 524.

Dupor, Bill, Tomiyuki Kitamura, and Takayuki Tsuruga. "Integrating Sticky Information and Sticky Prices" forthcoming in The Review of Economics and Statistics.

Edge, Rochelle M., Michael T. Kiley, and Jean-Philippe Laforte. 2005. "An Estimated DSGE Model of the US Economy." Manuscript.

Fabiani, S., C. Kwapil, M. Druant, I. Hernando, B. Landau, C. Loupias, F. Martins, T. Matha, R. Sabbatini, H. Stahl, A.C.J. Stokman, 2005. "The pricing behaviour of firms in the euro area new survey evidence," European Central Bank, Working Paper 535.

Fuhrer, Jeffrey C. 2000. "Habit Formation in Consumption and Its Implications for Monetary Policy Models," American Economic Review 90(3), 367-390.

Gali, Jordi and Mark Gertler. 1999. "Inflation dynamics: a structural econometric analysis," Journal of Monetary Economics 44, 195-222.

Gelman, Andrew, John B. Carlin, Hal S. Stern, and Donald B. Rubin, 2004. Bayesian Data Analysis, Chapman and Hall/CRC.

Gelman, Andrew, and Donald B. Rubin. 1992. Inference from iterative simulation using multiple sequences," Statistical Science 7, 457-511.

Gorodnichenko, Yuriy, and Serena Ng. 2008. "Estimation of DSGE models when data are persistent." Manuscript.

Gorodnichenko, Yuriy, and Matthew D. Shapiro. 2007. "Monetary policy when potential output is uncertain: Understanding the growth gamble of the 1990s," Journal of Monetary Economics 54(4), 1132-1162.

Grishchenko, Olesya. 2005. "Internal vs External Habit Formation: The relative importance for asset pricing." Manuscript.

Haltiwanger, John, and Michael Waldman, 1991. "Responders Versus Non-Responders: A New Perspective on Heterogeneity," Economic Journal 101, 1085-1102.

Hansen, Gary D. 1985. "Indivisible Labor and the Business Cycle," Journal of Monetary Economics 56, 309-327.

Hornstein, Andreas and Alexander L. Wolman. 2005. "Trend Inflation, Firm-Specific Capital, and Sticky-Prices," Federal Reserve Bank of Richmond Economic Quarterly 91(4), 57-83.

Horowitz, Joel L. 1998. "Bootstrap methods for covariance structures," Journal of Human Resources 33(1), 39-61.

Ireland, Peter. 2004. "Technology Shocks in the New Keynesian Model," Review of Economics and Statistics 86(4), 923-936.

Khan, Hashmat and Zhenhua Zhu. 2006. "Estimates of the Sticky-Information Phillips Curve for the United States," Journal of Money, Credit, and Banking 38(1), 195-207.

Kiley, Michael T. 2004. "Is Moderate-To-High Inflation Inherently Unstable?" Finance and Economics Discussion Series Working Paper \# 2004-43, Federal Reserve Board.

Kiley, Michael T. 2007. "A Quantitative Comparison of Sticky Price and Sticky Information Models of Price Setting," Journal of Money, Credit, and Banking 39 (1): 101-125 Suppl. S.

Kitamura, Tomiyuki. 2008. "Optimal Monetary Policy under Sticky Prices and Sticky Information," Manuscript. 
Klenow, Peter J., and Jonathan L. Willis, 2007. "Sticky information and sticky prices", Journal of Monetary Economics 54, 79-99.

Knotek, Edward S. II. 2008. "A Tale of Two Rigidities: Sticky-Prices in a Sticky-Information Environment," Manuscript.

Korenok, Oleg. 2008. "Empirical Comparison of Sticky Price and Sticky Information Models." Journal of Macroeconomics 30, 906-927.

Kydland, Finn E. and Edward C. Prescott. 1982. "Time to Build and Aggregate Fluctuations," Econometrica 50, 1435-1370.

Linde, Jesper. 2005. "Estimating New Keynesian Phillips Curves: A Full Information Maximum Likelihood Approach,” Journal of Monetary Economics 52(6), 1135-1149.

Mankiw, N. Gregory and Ricardo Reis. 2002. "Sticky Information Versus Sticky Prices: A Proposal to Replace the New Keynesian Phillips Curve," Quarterly Journal of Economics 117(4), 1295-1328.

Mankiw, N. Gregory and Ricardo Reis. 2003. "What Measure of Inflation Should a Central Bank Target?" Journal of the European Economic Association 1(5), 1058-1086.

Nakamura, Emi and Jon Steinsson. 2008. "Five Facts about Prices: A Reevaluation of Menu Cost Models," Quarterly Journal of Economics 123(4), 1415-1464.

Ravina, Enrichetta. 2004. "Keeping Up with the Joneses: Evidence from Micro Data". Manuscript.

Reis, Ricardo. 2006. "Inattentive Producers," Review of Economic Studies 73 (3), 793-821.

Rudd, Jeremy and Karl Whelan. 2006. "Can Rational Expectations Sticky-Price Models Explain Inflation Dynamics?" American Economic Review 96(1), 303-320.

Ruge-Murcia, Francisco J., 2003. "Methods to Estimate Stochastic General Equilibrium Models," mimeo.

Sargent, Thomas J., 1989. “Two Models of Measurements and the Investment Accelerator,” Journal of Political Economy 97(2), 251-287.

Sims, Christopher A. 2003. "Implications of Rational Inattention." Journal of Monetary Economics 50(3), 665-690.

Taylor, John B. 1993. "Discretion versus Policy Rules in Practice," Carnegie Rochester Conference Series on Public Policy 39, 195-214.

Taylor, John B. 1999. "Staggered Price and Wage Setting in Macroeconomics." in J.B. Taylorand M. Woodford, eds., Handbook of Macroeconomics, Amsterdam: Elsevier Science, NorthHolland, 1999 1009-1050.

Watson, Mark W. 1993. "Relative value of the objective function is relative to the hybrid model," Journal of Political Economy 101(6): 1011-1041.

Williams, John C. 2003. "Simple Rules for Monetary Policy," Economic Review of Federal Reserve Bank of San Francisco, 1-12.

Woodford, Michael. 2001. "Imperfect Common Knowledge and the Effects of Monetary Policy" in Knowledge, Information, and Expectations in Modern Macroeconomics: In Honor of Edmund Phelps, ed. by P. Aghion, R. Frydman, J. Stiglitz, and M. Woodford, Princeton University Press.

Woodford, Michael. 2003. Interest and Prices: Foundations of a Theory of Monetary Policy. Princeton: Princeton University Press.

Zbaracki, Mark J, Ritson M, Levy D, Dutta S, Bergen M, 2004. "Managerial and customer costs of price adjustment: Direct evidence from industrial markets," Review of Economics and Statistics 86(2): 514-533. 


\section{APPENDIX 1: Proof of Proposition 1}

Note first that, rewriting equation (7) in terms of relative price ratios in the steady-state yields

$$
1=\left[s_{1} \overline{p^{s p}}{ }^{1-\theta}+\left(1-s_{1}\right) \overline{p^{\#-}-\theta}\right] .
$$

so that if the relative optimal price is less than one, the sticky-price relative price ratio must be greater than one. The steady-state relative optimal price is given by

$$
\overline{p^{\#}}=\left[s_{1}\left(\frac{1-\delta_{s p}}{1-\theta \delta_{s p} \bar{\pi}^{\theta-1}}\right)\left(\frac{1-\gamma_{1}}{1-\gamma_{2}}\right)^{(1-\theta)(1+\omega \theta)}+\left(1-s_{1}\right)\right]^{1 /(1-\theta)} .
$$

Thus, if $\left(\frac{1-\delta_{s p}}{1-\delta_{s p} \bar{\pi}^{\theta-1}}\right)\left(\frac{1-\gamma_{1}}{1-\gamma_{2}}\right)^{(1-\theta) /(1+\omega \theta)}<1$, then $\overline{p^{\#}}<1$ and $\overline{p^{s p}}>1$.

Recall that $\gamma_{1}$ and $\gamma_{2}$ are given by $\gamma_{1} \equiv \delta_{s p} a \bar{R}^{-1} \bar{\pi}^{\theta}$ and $\gamma_{2} \equiv \delta_{s p} a \bar{R}^{-1} \bar{\pi}^{1+\theta(1+\omega)}$. The bond condition (3) evaluated in the steady-state yields $1=\beta \bar{R} /(a \bar{\pi})$ so we can rewrite $\gamma_{1}$ and $\gamma_{2}$ as $\gamma_{1} \equiv \delta_{s p} \beta \bar{\pi}^{\theta-1}$ and $\gamma_{2} \equiv \delta_{s p} \beta \bar{\pi}^{\theta(1+\omega)}$. Now define

$$
X \equiv\left(\frac{1-\delta_{s p}}{1-\delta_{s p} \bar{\pi}^{\theta-1}}\right)\left(\frac{1-\gamma_{1}}{1-\gamma_{2}}\right)^{(1-\theta) /(1+\omega \theta)}=\left(\frac{1-\delta_{s p}}{1-\delta_{s p} \bar{\pi}^{\theta-1}}\right)\left(\frac{1-\delta_{s p} \beta \bar{\pi}^{\theta-1}}{1-\delta_{s p} \beta \bar{\pi}^{\theta(1+\omega)}}\right)^{(1-\theta) /(1+\omega \theta)} .
$$

Note first that $\left.X\right|_{\bar{\pi}=1}=1$, so without trend inflation the average relative price of sticky-price firms is 1 in the steady-state. A well-defined steady-state requires $\gamma_{1}<1, \gamma_{2}<1$, and $\delta_{s p} \bar{\pi}^{1-\theta}<1$. Thus,

$$
X \leq 1 \Leftrightarrow \beta \geq \frac{1-C}{\delta_{s p} \bar{\pi}^{1-\theta}\left(\bar{\pi}^{1+\omega \theta}-C\right)} \equiv \beta^{*}\left(\theta, \omega, \delta_{s p}, \bar{\pi}\right)
$$

where $C \equiv\left(\frac{1-\delta_{s p} \bar{\pi}^{\theta-1}}{1-\delta_{s p}}\right)^{(1+\omega \theta) /(\theta-1)}$. Note that for positive trend inflation $(\bar{\pi}>1), C<1$ and $\bar{\pi}^{1+\omega \theta}-C>0$. 


\section{APPENDIX 2: Technical Details on Estimation}

To estimate the model, we use a Markov Chain Monte Carlo (MCMC) method developed in Chernozhukov and Hong (2003; henceforth CH). CH show that, under certain conditions, the parameter estimates as well as their standard errors can be computed directly from the generated chains. Specifically, the average value for a parameter in a chain will provide a consistent estimate if this parameter is globally identified and other conditions standard for GMM estimation are satisfied. Likewise, standard errors can be calculated as (appropriately adjusted if necessary) standard deviation of parameter draws in the generated chain.

We employ the Hastings-Metropolis algorithm to implement CH's estimation method. Specifically our procedure to construct chains of length $N$ can be summarized as follows:

Step 1: Draw $\Theta^{(n)}$, a candidate vector of parameter values for the chain's $n+1$ state, as $\Theta^{(n)}=\Psi^{(n)}+\phi^{(n)}$ where $\Psi^{(n)}$ is the current $n$ state of the vector of parameter values in the chain, $\phi^{(n)}$ is a vector of i.i.d. shocks taken from $N(0, \Phi), \Phi$ is a diagonal matrix.

Step 2: Take the $n+1$ state of the chain as

$$
\Psi^{(n+1)}=\left\{\begin{array}{l}
\Theta^{(n)} \text { with probability } \min \left\{1, \exp \left[J\left(\Psi^{(n)}\right)-J\left(\Theta^{(n)}\right)\right]\right\} \\
\Psi^{(n)} \text { otherwise }
\end{array}\right.
$$

where $J\left(\Psi^{(n)}\right)$ is the value of the objective function at the current state of the chain and $J\left(\Theta^{(n)}\right)$ is the value of the objective function using the candidate vector of parameter values. Our choices for initial values $\Psi^{(0)}$ and size of the shocks $\phi^{(n)}$ described by $\Phi$ are summarized in Appendix Table A1. The initial values for most variables are chosen to more rapidly approach the global minimum, while $\Phi$ is calibrated to about one percent of the parameter value and then adjusted on the fly for the first 100,000 draws to generate 0.3 acceptance rates of candidate draws, as proposed in Gelman et al (2004).

$\mathrm{CH}$ show that $\bar{\Psi}=\frac{1}{N} \sum_{n=1}^{N} \Psi^{(n)}$ is a consistent estimate of $\Psi$ under standard regularity assumptions of GMM estimators. $\mathrm{CH}$ also prove that if the optimal weight matrix is used in the GMM objective function, then $V=\frac{1}{N} \sum_{n=1}^{N}\left(\Psi^{(n)}-\bar{\Psi}\right)^{2}=\operatorname{var}\left(\Psi^{(n)}\right)$ is a consistent estimate of the asymptotic covariance matrix of the parameter estimates. In a more general case with a given weight matrix $W$ in the GMM objective function, the covariance matrix for the parameter estimates is given by $T^{-1} V \Omega V$ where $\Omega=D W \Gamma W D^{\prime}, D$ is the Jacobian of the moment conditions, $T$ is sample size, and $\Gamma$ is the covariance of moment conditions. ${ }^{37} \mathrm{CH}$ show that these estimates of sampling

\footnotetext{
${ }^{37}$ Although one may use Newey-West estimate of $\Gamma$, we found, in line with Horowitz (1998), that bootstrap-based estimates of $\Gamma$ improve the finite sample properties of the covariance estimators.
} 
uncertainty recover asymptotic standard errors well. However, in highly nonlinear models and in short samples, one may be inclined to employ bootstrap-based standard errors to have better coverage. Given that our sample is fairly short, we prefer the latter approach. Our bootstrap procedure can be summarized as follows: a) we estimate a VAR; b) resample the residuals; c) construct new series using the resampled residuals and estimated VAR; d) estimate the parameters on newly created data; ${ }^{38}$ e) repeat steps b)-d) many times; f) compute standard errors based on bootstrap replications. We found in simulations that this procedure works very well.

We use 500,000 draws for our baseline and robustness estimates, and drop the first 100,000 draws ("burn-in" period). We run a series of diagnostics to check the properties of the resulting distributions from the generated chains. We present results only for the baseline specification. Diagnostics for other specifications are similar and hence not reported. First, Appendix Figure A1 shows the histograms of parameter values in the generated chain. The distributions are single peaked and generally bell-shaped although the distributions are not symmetric for some parameters. The three exceptions are $s_{3}, \delta_{s i}$, and $\sigma_{m e, r}$ which converge to the boundary. Second, well-identified parameters should exhibit a U-shaped pattern for the lower envelope of the draws against the value of the objective function. Appendix Figure A2 plots the distribution of parameter draws against the value of the objective function and we clearly observe the desired pattern. Third, we diagnose whether our chain converges to a stationary distribution. We use the approach developed in Gelman and Rubin (1992) which examines convergence across multiple chains. Appendix Figure A3 shows the dynamics of between variation of generated chains $B_{N}=\frac{1}{M} \sum_{m=1}^{M}\left(\bar{\Psi}_{(m)}-\bar{\Psi}\right)^{2}$ and within variation across chains $W_{N}=\frac{1}{M N} \sum_{m=1}^{M} \sum_{n=1}^{N}\left(\Psi_{(m)}^{(n)}-\bar{\Psi}_{(m)}\right)^{2}$ as a function of chain length $N$ where $\bar{\Psi}_{(m)}=\frac{1}{N} \sum_{n=1}^{N} \Psi_{(m)}^{(n)}$ is the average of parameter values in chain $m, \bar{\Psi}=\frac{1}{M} \sum_{m=1}^{M} \bar{\Psi}_{(m)}$ is the average of parameter values across chains, $\Psi_{(m)}^{(n)}$ is the parameter value in chain $m$ in draw $n, M$ is the number of chains Consistent with convergence, $B_{N}$ shrinks to zero and $W_{N}$ stabilizes as the chain length $N$ increases. Likewise, Appendix Figure A4 shows that $R_{N}=\sqrt{\left(\frac{N-1}{N} W_{N}+B_{N}\right) / W_{N}}$, the convergence statistic suggested by Gelman and Rubin (1992), converges to one. Although Appendix Figures A3 and A4 suggest that the required chain length is about one million draws, Appendix Figure A5 demonstrates that a chain with 500,000 draws yields estimates very close to estimates generated from longer chains and hence in our simulations we use only 500,000-draw chains.

\footnotetext{
${ }^{38}$ Note that we did not use the MCMC procedure to estimate the parameters, but rather a built-in minimizing function starting at our estimated values.
} 
Table 1: Estimation Results:

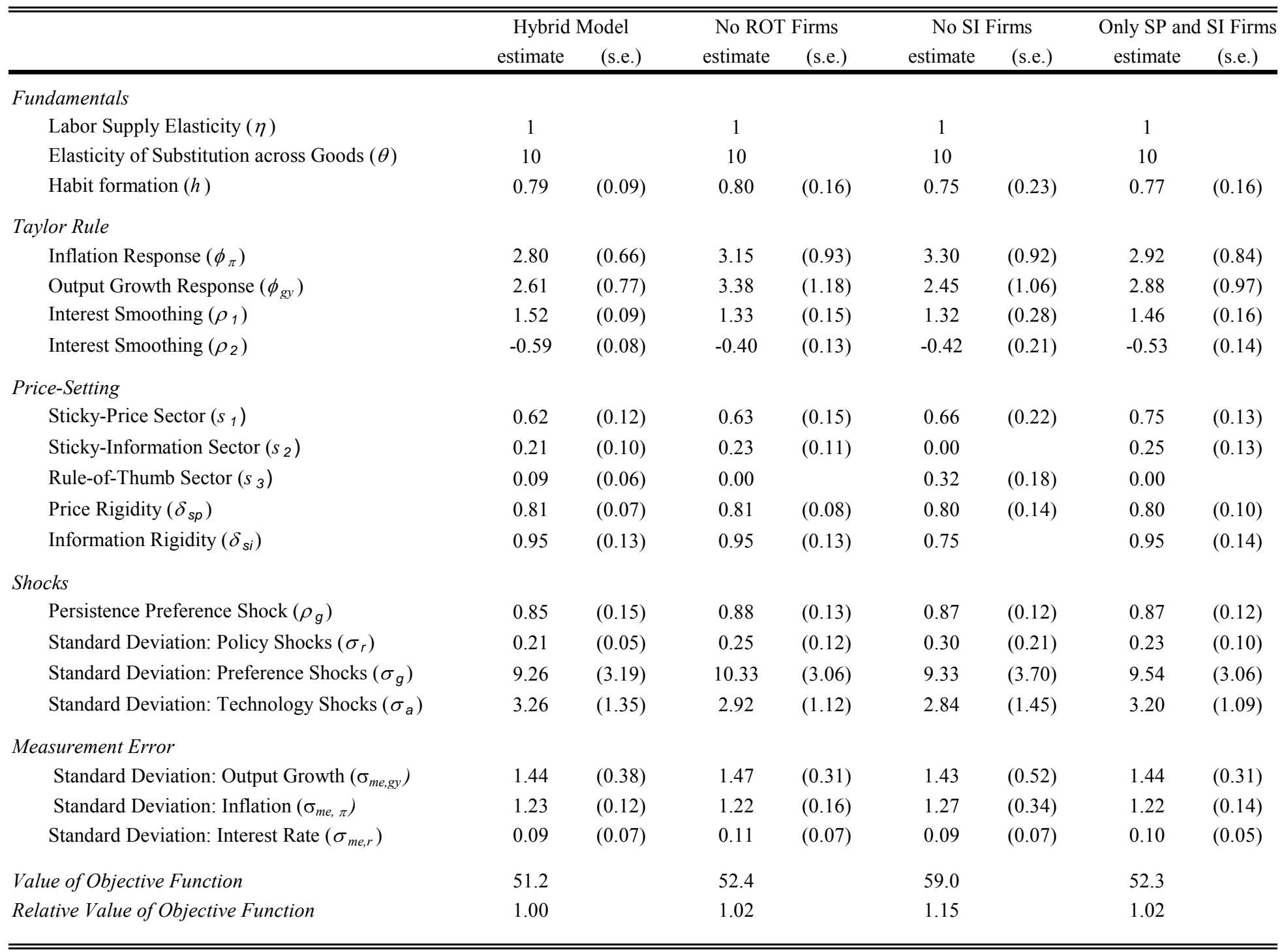

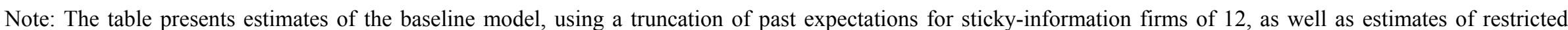

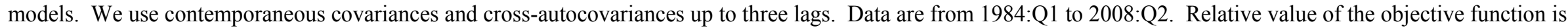

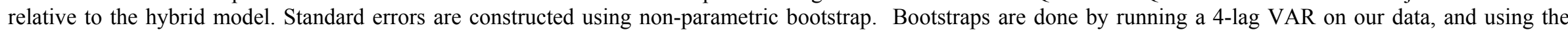

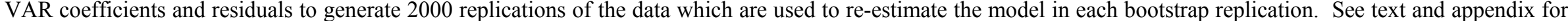
details on estimation approach. 
Table 2: Estimates of the Pure Models:

\begin{tabular}{|c|c|c|c|c|c|c|}
\hline & \multicolumn{2}{|c|}{ Sticky-Price Model } & \multicolumn{2}{|c|}{ Sticky-Info Model } & \multicolumn{2}{|c|}{ Fully Flexible Model } \\
\hline & estimate & (s.e.) & estimate & (s.e.) & estimate & (s.e.) \\
\hline \multicolumn{7}{|l|}{ Fundamentals } \\
\hline Labor Supply Elasticity $(\eta)$ & 1 & & 1 & & 1 & \\
\hline Elasticity of Substitution across Goods $(\theta)$ & 10 & & 10 & & 10 & \\
\hline Habit formation $(h)$ & 0.69 & $(0.21)$ & 0.82 & & 1.00 & $(0.03)$ \\
\hline \multicolumn{7}{|l|}{ Taylor Rule } \\
\hline Inflation Response $\left(\phi_{\pi}\right)$ & 3.46 & $(0.92)$ & 1.70 & $(0.85)$ & 1.74 & $(0.71)$ \\
\hline Output Growth Response $\left(\phi_{g y}\right)$ & 2.44 & $(1.19)$ & 4.52 & $(1.31)$ & 0.76 & $(0.44)$ \\
\hline Interest Smoothing $\left(\rho_{1}\right)$ & 1.29 & $(0.22)$ & 1.45 & $(0.14)$ & 1.15 & $(0.46)$ \\
\hline Interest Smoothing $\left(\rho_{2}\right)$ & -0.39 & $(0.19)$ & -0.50 & $(0.14)$ & -0.67 & $(0.24)$ \\
\hline \multicolumn{7}{|l|}{ Price-Setting } \\
\hline Sticky-Price Sector $\left(s_{1}\right)$ & 1.00 & & 0.00 & & 0.00 & \\
\hline Sticky-Information Sector $\left(s_{2}\right)$ & 0.00 & & 1.00 & & 0.00 & \\
\hline Rule-of-Thumb Sector $\left(s_{3}\right)$ & 0.00 & & 0.00 & & 0.00 & \\
\hline Price Rigidity $\left(\delta_{s p}\right)$ & 0.80 & $(0.09)$ & & & & \\
\hline Information Rigidity $\left(\delta_{s i}\right)$ & & & 0.90 & $(0.07)$ & & \\
\hline \multicolumn{7}{|l|}{ Shocks } \\
\hline Persistence Preference Shock $\left(\rho_{g}\right)$ & 0.88 & $(0.11)$ & 0.86 & $(0.14)$ & 1.00 & $(0.28)$ \\
\hline Standard Deviation: Policy Shocks $\left(\sigma_{r}\right)$ & 0.27 & $(0.17)$ & 0.34 & $(0.15)$ & 0.29 & $(0.20)$ \\
\hline Standard Deviation: Preference Shocks $\left(\sigma_{g}\right)$ & 9.54 & $(3.08)$ & 9.29 & $(4.25)$ & 9.87 & $(4.68)$ \\
\hline Standard Deviation: Technology Shocks $\left(\sigma_{a}\right)$ & 3.05 & $(1.27)$ & 0.57 & $(0.42)$ & 3.54 & $(1.65)$ \\
\hline \multicolumn{7}{|l|}{ Measurement Error } \\
\hline Standard Deviation: Output Growth $\left(\sigma_{m e, g y}\right)$ & 1.37 & $(0.43)$ & 1.44 & $(0.40)$ & 1.91 & $(0.25)$ \\
\hline Standard Deviation: Inflation $\left(\sigma_{m e, \pi}\right)$ & 1.24 & $(0.14)$ & 1.17 & $(0.16)$ & 0.93 & $(0.49)$ \\
\hline Standard Deviation: Interest Rate $\left(\sigma_{m e, r}\right)$ & 0.09 & $(0.07)$ & 0.12 & $(0.09)$ & 1.52 & $(0.15)$ \\
\hline Value of Objective Function & 60.0 & & 92.3 & & 1431.3 & \\
\hline Relative Value of Objective Function & 1.17 & & 1.80 & & 27.96 & \\
\hline
\end{tabular}

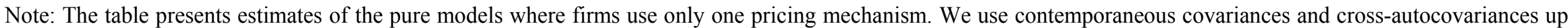

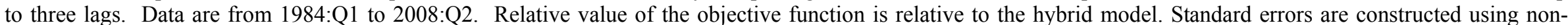

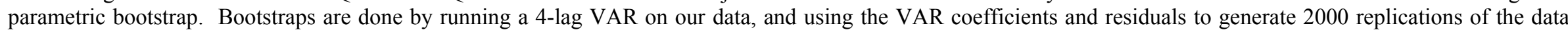
which are used to re-estimate the model in each bootstrap replication. See text and appendix for details on estimation approach. 
Table 3: Variance Decomposition

\begin{tabular}{lccc}
\hline \hline & \multicolumn{3}{c}{ Source of Variance of Growth in Output } \\
\cline { 2 - 4 } \multicolumn{1}{c}{ Model } & Policy & Preference & Technology \\
\hline Hybrid & 5 & 85 & 10 \\
Sticky-Price & 5 & 72 & 23 \\
Sticky-Info & 20 & 80 & 0 \\
Flexible & 0 & 67 & 33 \\
& \multicolumn{2}{c}{ Source of Variance of Inflation } \\
\cline { 2 - 4 } \multicolumn{1}{c}{ Model } & Policy & Preference & Technology \\
\hline Hybrid & 5 & 25 & 70 \\
Sticky-Price & 5 & 41 & 54 \\
Sticky-Info & 50 & 44 & 7 \\
Flexible & 57 & 29 & 14 \\
& Source of Variance of Interest Rates \\
\multicolumn{1}{c}{ Model } & Policy & Preference & Technology \\
\hline Hybrid & 10 & 90 & 0 \\
Sticky-Price & 5 & 95 & 0 \\
Sticky-Info & 25 & 75 & 0 \\
Flexible & 0 & 67 & 33 \\
\hline \hline
\end{tabular}

Note: Table presents variance decompositions given the parameter estimates for the hybrid model from Table 1 and the pure models from Table 2. Horizon is four quarters. 
Table 4: Robustness of Estimates:

\begin{tabular}{|c|c|c|c|c|c|c|c|c|c|c|}
\hline & \multicolumn{2}{|c|}{ More moments } & \multicolumn{2}{|c|}{$\begin{array}{c}\text { Diagonal } \\
\text { Weighting Matrix } \\
\end{array}$} & \multicolumn{2}{|c|}{ Indivisible Labor } & \multicolumn{2}{|c|}{$\begin{array}{l}\text { Response to } \\
\text { Output Gap }\end{array}$} & \multicolumn{2}{|c|}{$\begin{array}{l}\text { AR(1) Interest } \\
\text { Smoothing }\end{array}$} \\
\hline & estimate & (s.e.) & estimate & (s.e.) & estimate & (s.e.) & estimate & (s.e.) & estimate & (s.e.) \\
\hline \multicolumn{11}{|l|}{ Fundamentals } \\
\hline Labor Supply Elasticity $(\eta)$ & 1 & & 1 & & $\infty$ & & 1 & & 1 & \\
\hline Elasticity of Substitution across Goods $(\theta)$ & 10 & & 10 & & 10 & & 10 & & 10 & \\
\hline Habit formation $(h)$ & 0.87 & $(0.09)$ & 0.75 & $(0.18)$ & 0.81 & $(0.06)$ & 0.81 & $(0.12)$ & 0.81 & $(0.19)$ \\
\hline \multicolumn{11}{|l|}{ Taylor Rule } \\
\hline Inflation Response $\left(\phi_{\pi}\right)$ & 2.58 & $(0.93)$ & 3.04 & $(0.80)$ & 2.13 & $(0.52)$ & 2.67 & $(0.73)$ & 3.48 & $(0.98)$ \\
\hline Output Growth Response $\left(\phi_{g y}\right)$ & 1.87 & $(0.87)$ & 2.75 & $(1.09)$ & 2.83 & $(0.86)$ & 2.73 & $(0.90)$ & 4.05 & $(1.18)$ \\
\hline Output Gap Response $\left(\phi_{x}\right)$ & 0.00 & & 0.00 & & 0.00 & & 0.02 & $(0.01)$ & 0.00 & \\
\hline Interest Smoothing $\left(\rho_{1}\right)$ & 1.74 & $(0.09)$ & 0.66 & $(0.16)$ & 1.50 & $(0.20)$ & 1.60 & $(0.17)$ & 0.91 & $(0.11)$ \\
\hline Interest Smoothing $\left(\rho_{2}\right)$ & -0.79 & $(0.08)$ & 0.14 & $(0.09)$ & -0.57 & $(0.17)$ & -0.66 & $(0.15)$ & 0.00 & \\
\hline \multicolumn{11}{|l|}{ Price-Setting } \\
\hline Sticky-Price Sector $\left(s_{1}\right)$ & 0.57 & $(0.17)$ & 0.48 & $(0.18)$ & 0.49 & $(0.14)$ & 0.61 & $(0.15)$ & 0.60 & $(0.14)$ \\
\hline Sticky-Information Sector $\left(s_{2}\right)$ & 0.24 & $(0.12)$ & 0.16 & $(0.10)$ & 0.00 & $(0.00)$ & 0.23 & $(0.10)$ & 0.15 & $(0.07)$ \\
\hline Rule-of-Thumb Sector $\left(s_{3}\right)$ & 0.11 & $(0.07)$ & 0.18 & $(0.12)$ & 0.51 & $(0.14)$ & 0.08 & $(0.05)$ & 0.09 & $(0.05)$ \\
\hline Price Rigidity $\left(\delta_{s p}\right)$ & 0.82 & $(0.11)$ & 0.76 & $(0.15)$ & 0.85 & $(0.02)$ & 0.80 & $(0.12)$ & 0.81 & $(0.09)$ \\
\hline Information Rigidity $\left(\delta_{s i}\right)$ & 0.95 & $(0.15)$ & 0.65 & $(0.24)$ & 0.52 & $(0.16)$ & 0.95 & $(0.15)$ & 0.94 & $(0.16)$ \\
\hline \multicolumn{11}{|l|}{ Shocks } \\
\hline Persistence Preference Shock $\left(\rho_{g}\right)$ & 0.79 & $(0.15)$ & 0.85 & $(0.11)$ & 0.85 & $(0.23)$ & 0.84 & $(0.15)$ & 0.89 & $(0.08)$ \\
\hline Standard Deviation: Policy Shocks $\left(\sigma_{r}\right)$ & 0.02 & $(0.01)$ & 0.89 & $(0.49)$ & 0.39 & $(0.13)$ & 0.15 & $(0.08)$ & 0.47 & $(0.22)$ \\
\hline Standard Deviation: Preference Shocks $\left(\sigma_{g}\right)$ & 11.70 & $(4.31)$ & 10.61 & $(3.75)$ & 8.66 & $(3.25)$ & 9.52 & $(3.99)$ & 10.63 & $(3.35)$ \\
\hline Standard Deviation: Technology Shocks $\left(\sigma_{a}\right)$ & 3.46 & $(1.54)$ & 1.56 & $(0.95)$ & 0.85 & $(0.39)$ & 3.32 & $(1.32)$ & 2.49 & $(1.00)$ \\
\hline \multicolumn{11}{|l|}{ Measurement Error } \\
\hline Standard Deviation: Output Growth $\left(\sigma_{m e, g y}\right)$ & 1.28 & $(0.48)$ & 1.30 & $(0.47)$ & 1.42 & $(0.53)$ & 1.45 & $(0.37)$ & 1.50 & $(0.32)$ \\
\hline Standard Deviation: Inflation $\left(\sigma_{m e, \pi}\right)$ & 1.33 & $(0.19)$ & 1.19 & $(0.20)$ & 1.20 & $(0.44)$ & 1.24 & $(0.15)$ & 1.20 & $(0.18)$ \\
\hline Standard Deviation: Interest Rate $\left(\sigma_{m e, r}\right)$ & 0.20 & $(0.13)$ & 0.51 & $(0.29)$ & 0.10 & $(0.04)$ & 0.12 & $(0.08)$ & 0.10 & $(0.06)$ \\
\hline Value of Objective Function & 123.4 & & 4.3 & & 73.1 & & 50.9 & & 56.8 & \\
\hline Relative Value of Objective Function & NA & & NA & & 1.43 & & 0.99 & & 1.11 & \\
\hline
\end{tabular}

Note: The table presents robustness estimates of the baseline model. The truncation of past expectations for sticky-information firms is 12 . We use contemporaneous covariances and cross-autocovariances up to three lags unless otherwise specified. Data are from 1984:Q1 to 2008:Q2. Relative value of the objective function, wherever relevant, is relative to the hybrid model. In the scenario "More moments", we use contemporaneous covariances and crossautocovariances up to eight lags. Standard errors are constructed using non-parametric bootstrap. Bootstraps are done by running a 4-lag VAR on our data, and using the VAR coefficients and residuals to generate 2000 replications of the data which are used to re-estimate the model in each bootstrap replication. See text and appendix for details on estimation approach. 
Figure 1: Autocorrelations of Observable Variables
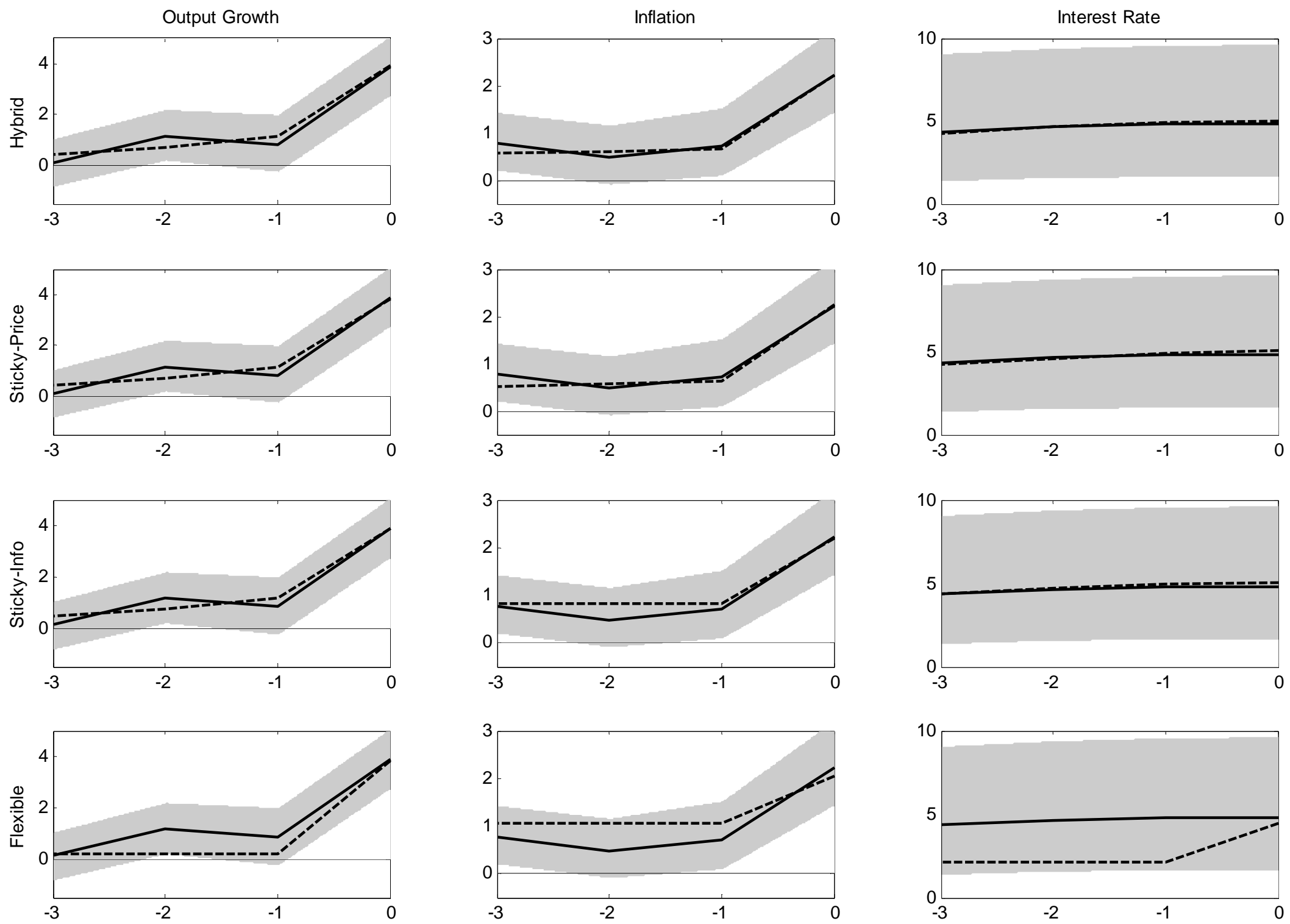

Note: The figure plots autocovariances of the observable variables in the data (1984:Q1-2008:Q2), as the black bold lines, as well as those predicted by the hybrid model and pure models (using estimates in Tables 1 and 2), as the bold black dashed lines. The grey shaded areas are bootstrapped $95 \%$ confidence intervals. Bootstraps are done by running a 4-lag VAR on our data, and using the VAR coefficients and residuals to generate 2000 replications of the data, from which we generate a distribution of autocovariances. The horizontal axis indicates the timing in quarters of the lagged variable used in the autocovariance. 
Figure 2: Cross-Correlations of Observable Variables
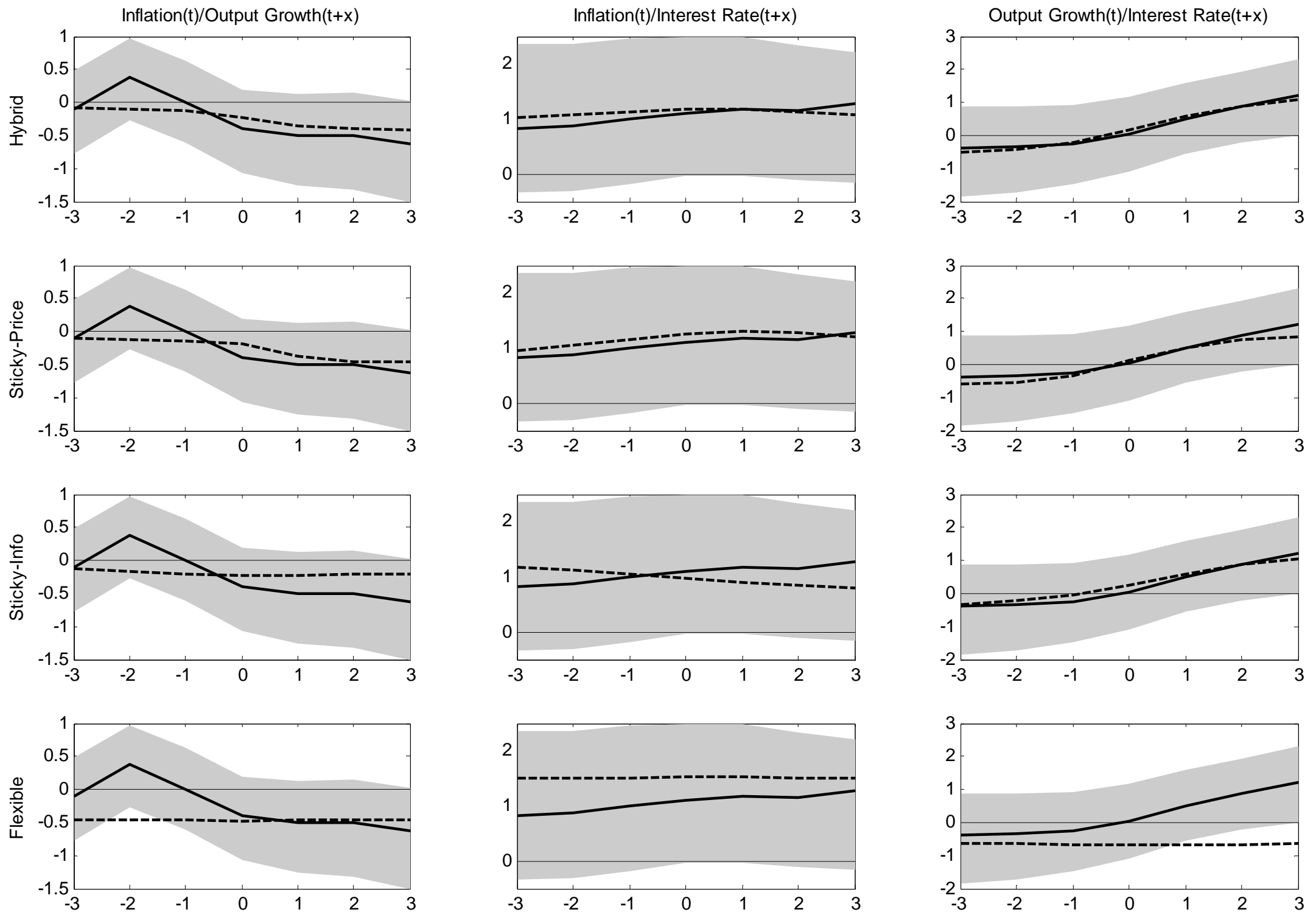

Note: The figure plots cross-autocovariances of the observable variables: output growth $(g y)$, inflation $(\pi)$, and interest rates $(r)$ in the data (1984:Q1-2008:Q2) and those predicted by the hybrid model as well as those predicted by the pure models (using estimates in Table 1). Black solid lines are from datawhile the bold dashed black lines are those of each model. The grey shaded areas are bootstrapped $95 \%$ confidence intervals. Bootstraps are done by running a 4-lag VAR on our data, and using the VAR coefficients and residuals to generate 2000 replications of the data, from which we generate a distribution of cross-autocovariances. The horizontal axis indicates the timing of the variable used in the cross-autocovariances (negative numbers indicate lags, positive numbers are leads). 
Figure 3. Impulse response functions
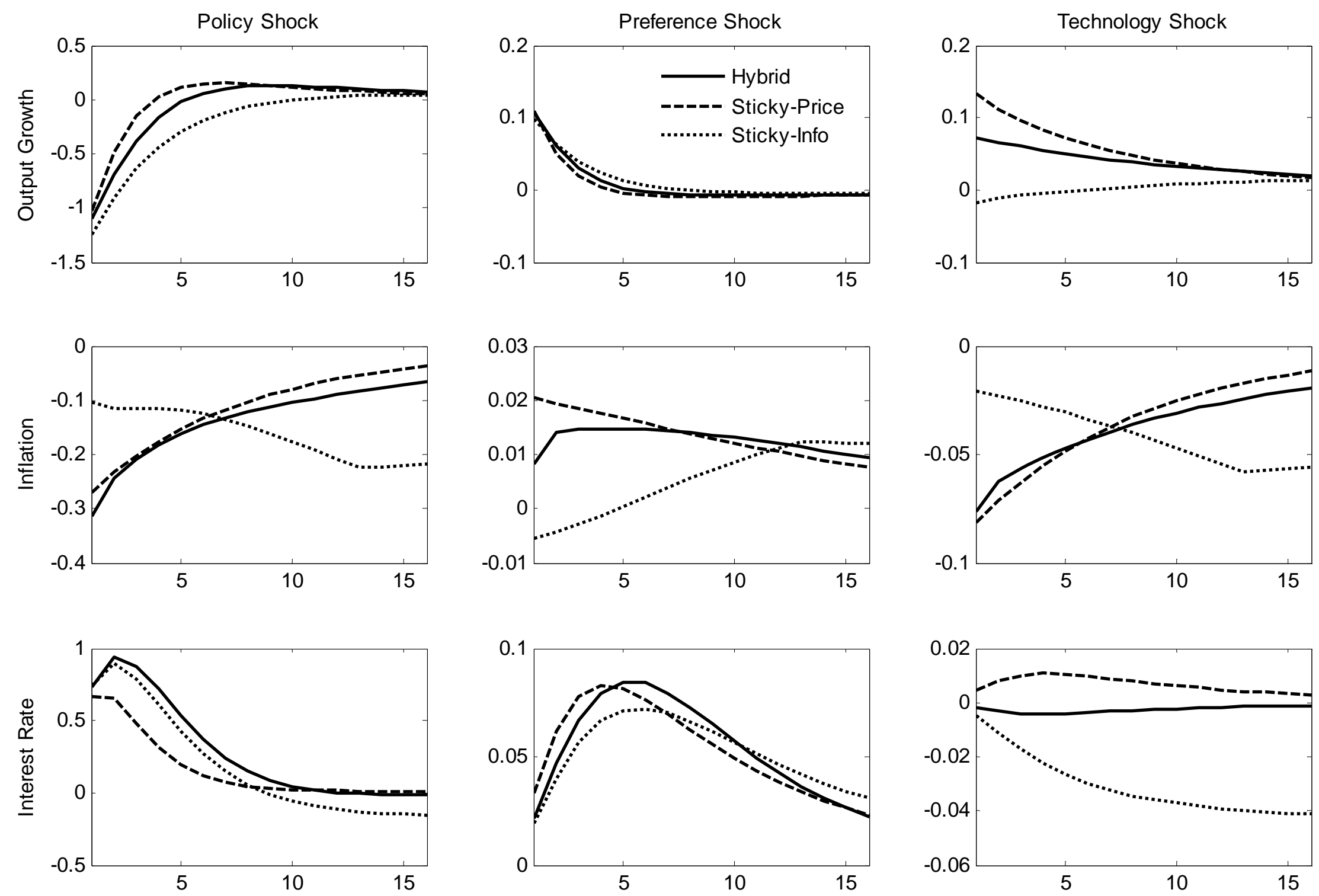

Note: The figure plots impulse responses (percent deviation from steady-state) of baseline (hybrid), pure sticky-price and pure sticky-information models (based on estimates reported in Tables 1 and 2) to a 1-unit innovation to monetary policy, preference shock, and technology. Time is in quarters on the horizontal axis. 
Figure 4: Sector-Specific vs. Pure Model Inflation
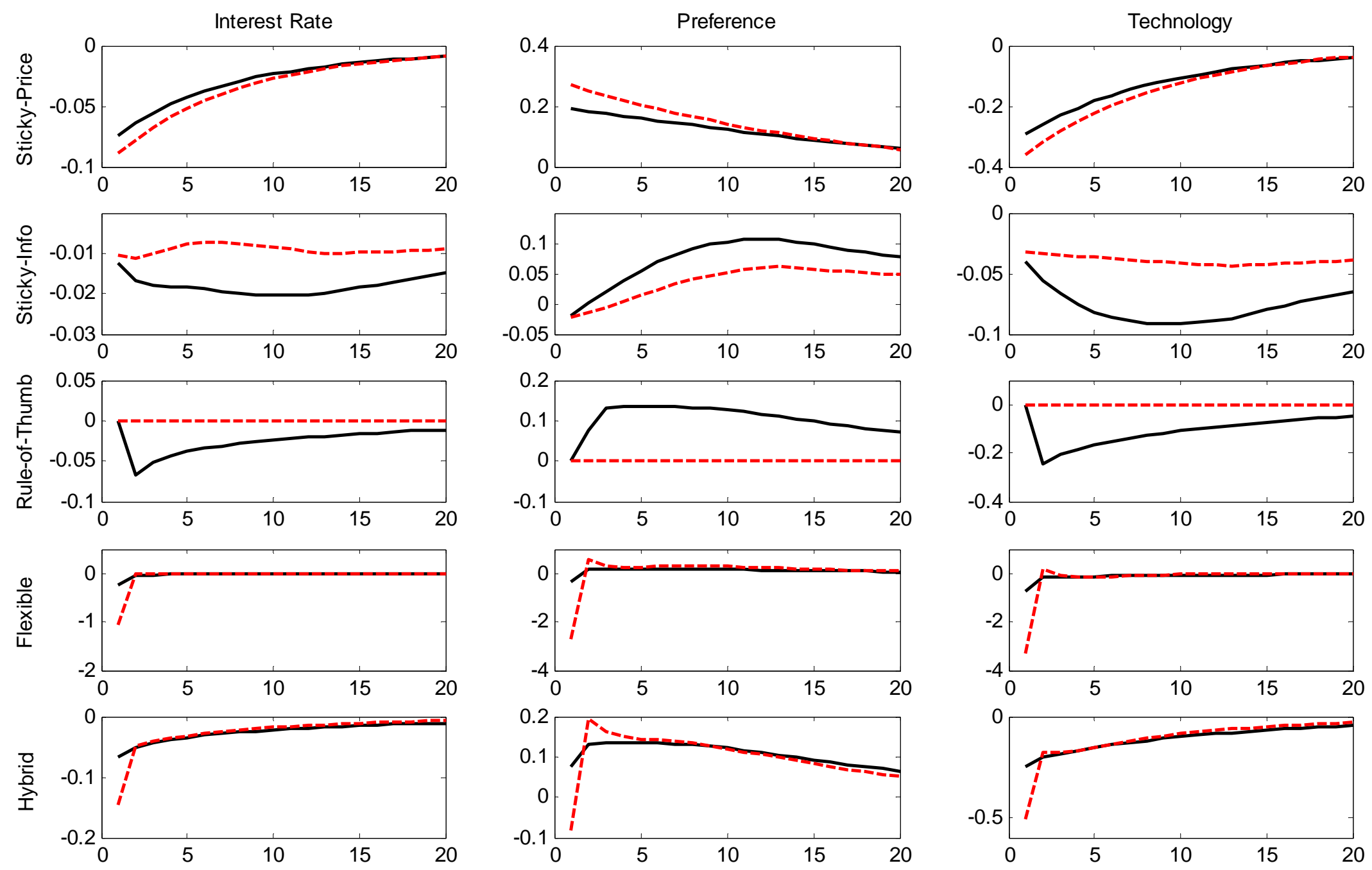

Note: The figure displays the response of inflation (percent deviation from steady-state) to shocks (labeled on top). Black solid lines indicate the response of inflation in each sector (labeled at left) within the hybrid model (using estimates of Table 1) while the red dash lines indicate the response of a pure model consisting only of that sector's type of firms (i.e., $s_{j}=1$ for sector $j$ ). The bottom row compares the response of aggregate inflation in the hybrid model (in black solid lines) to a weighted average of inflation rates from the pure models (red dashed lines), where the weights are the effective weights $\left(s{ }^{C P I}\right)$ of each sector from the baseline estimates. Baseline parameter estimates are used in each case. Time is in quarters on the horizontal axis. 
Figure 5: Robustness of Estimates to Elasticity of Substitution $(\theta)$

Panel A: Share of firms

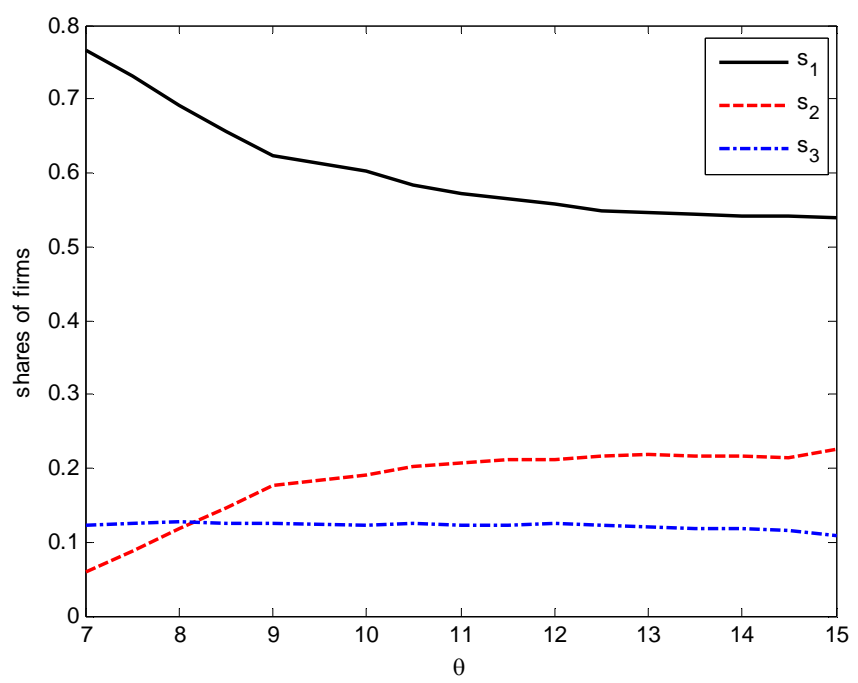

Panel C: fit of the model

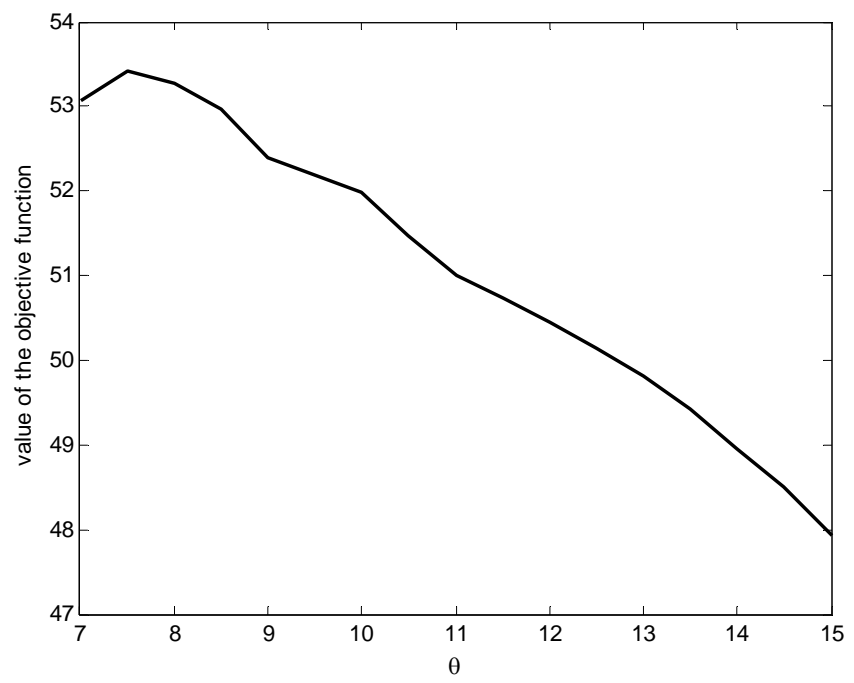

Panel B: price and information stickiness

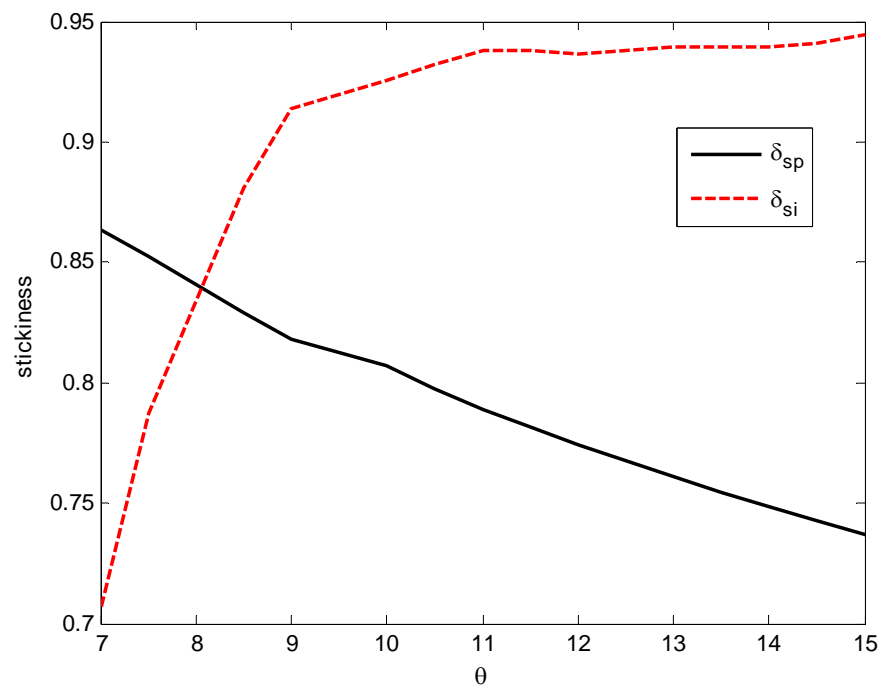

Note: The panels display estimation results of the baseline model for different values of $\theta$, as indicated on the horizontal axis of each panel. For each value of $\theta$, we ran a chain of 500,000 iterations, dropping the first 100,000 iterations. Panel A presents the estimated shares of sticky price $\left(s_{1}\right)$, sticky-information $\left(s_{2}\right)$, and rule-of-thumb firms $\left(s_{3}\right)$ for different values of $\theta$. Panel B presents the estimated levels of price rigidity $\left(\delta_{s p}\right)$ and informational rigidity $\left(\delta_{s i}\right)$ for different values of $\theta$. Panel C presents values of the objective function (averaged across chains) for each value of $\theta$. 
Loss function $L_{1}$

Panel A: Baseline hybrid model.

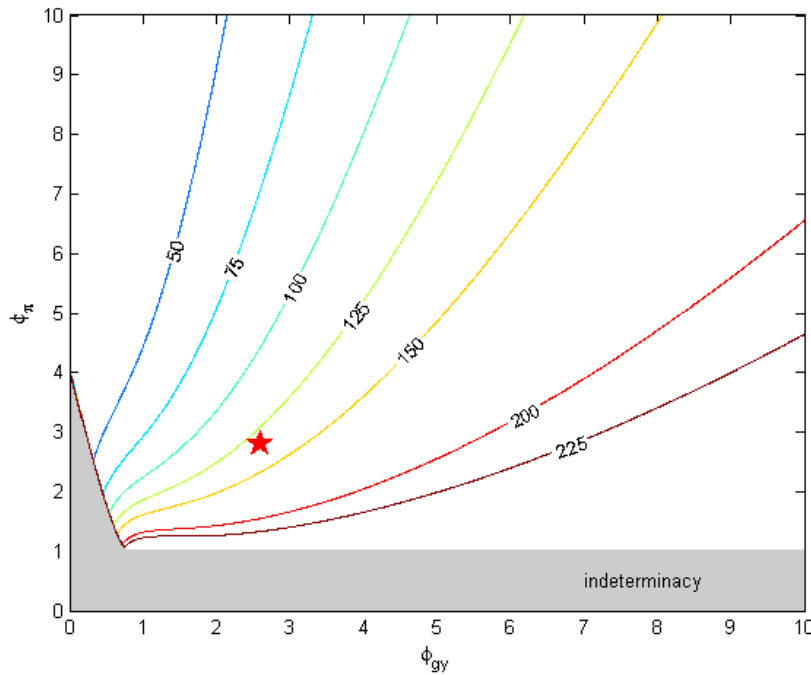

Figure 6. Welfare isoloss maps.

Loss function $L_{2}$

Panel B: Ratio of the relative map for pure sticky-price model to the relative map for the hybrid model.
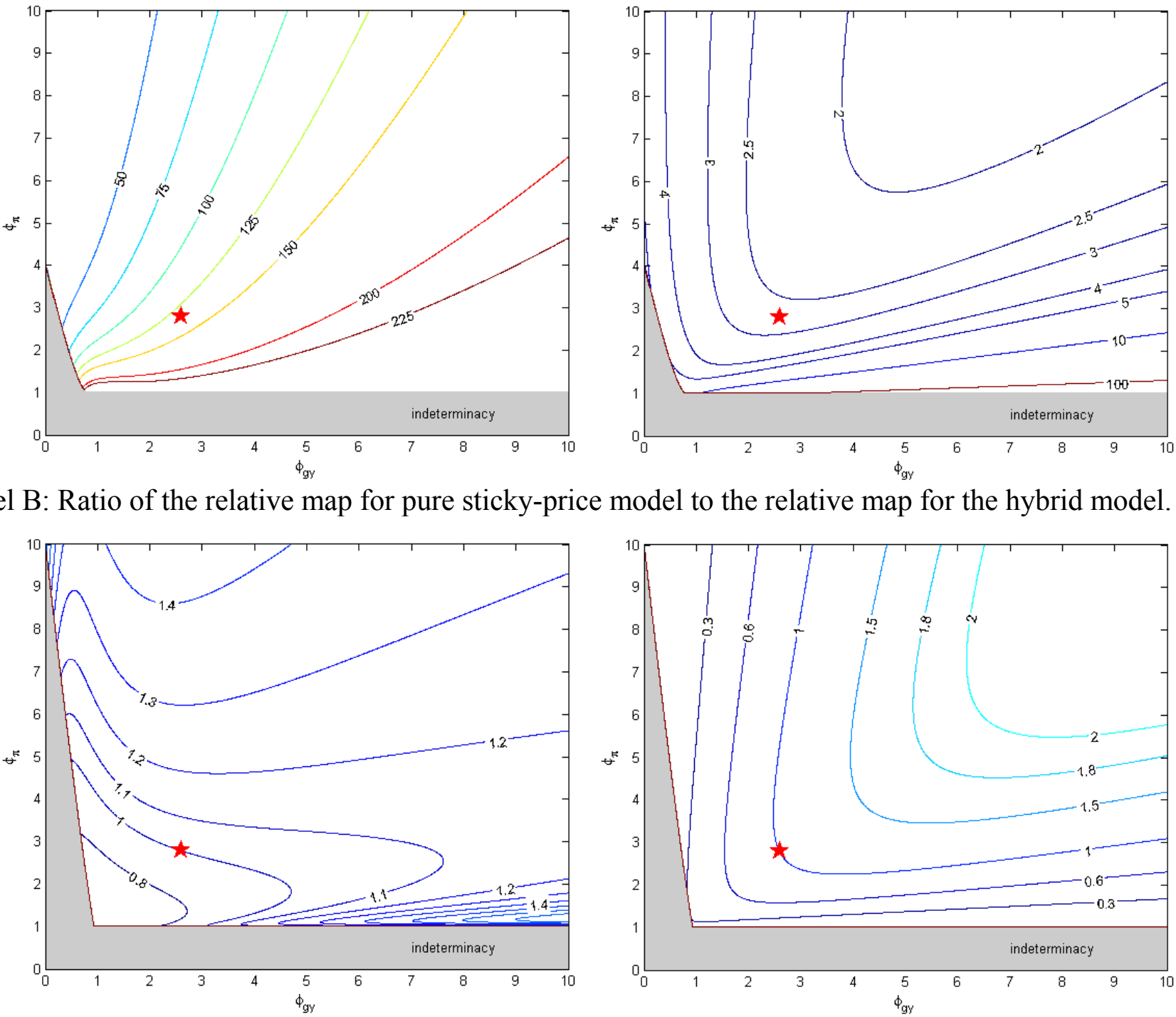

Panel C: Ratio of the relative map for pure sticky-information model to the relative map for the hybrid model.

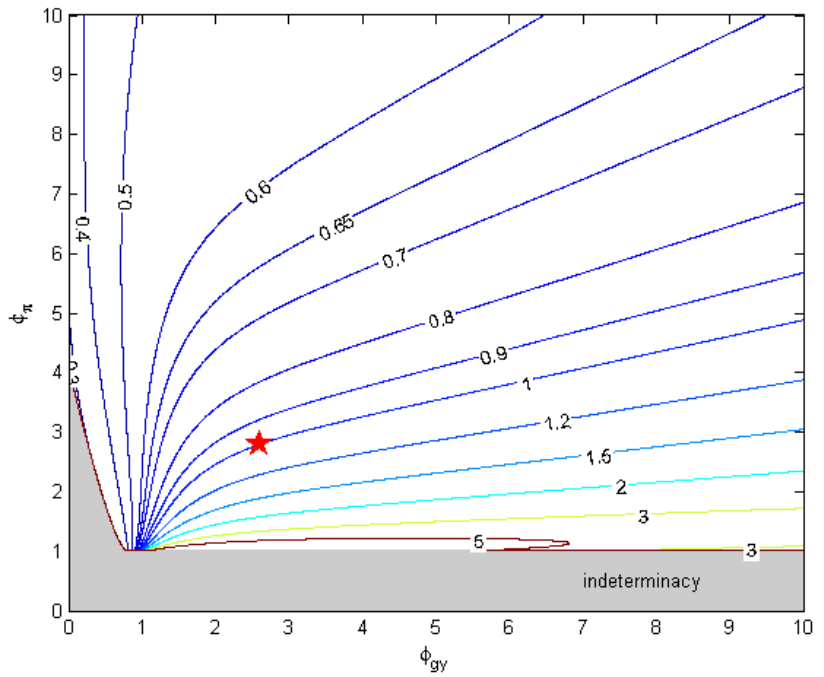

(continued on next page)

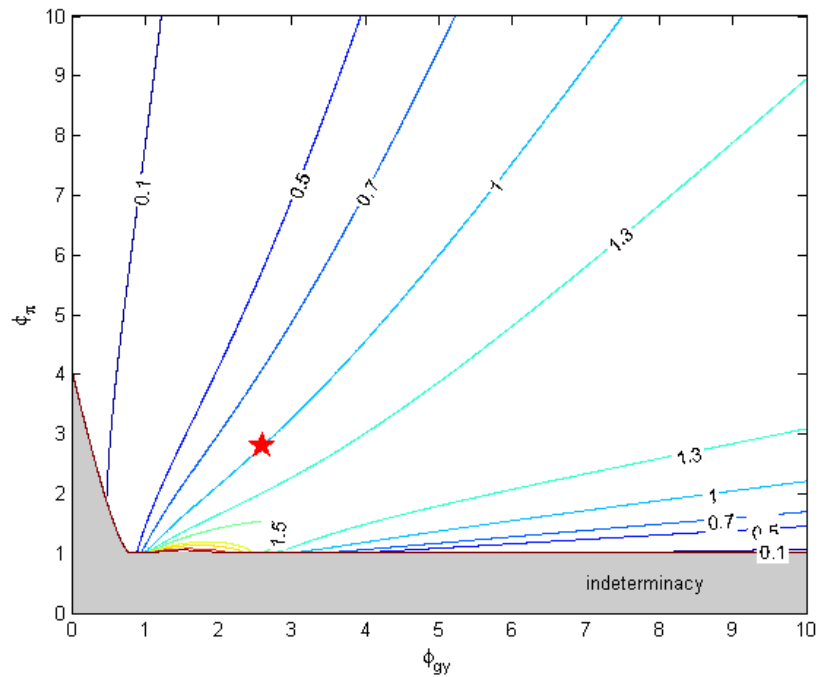


Panel D. Price level targeting.
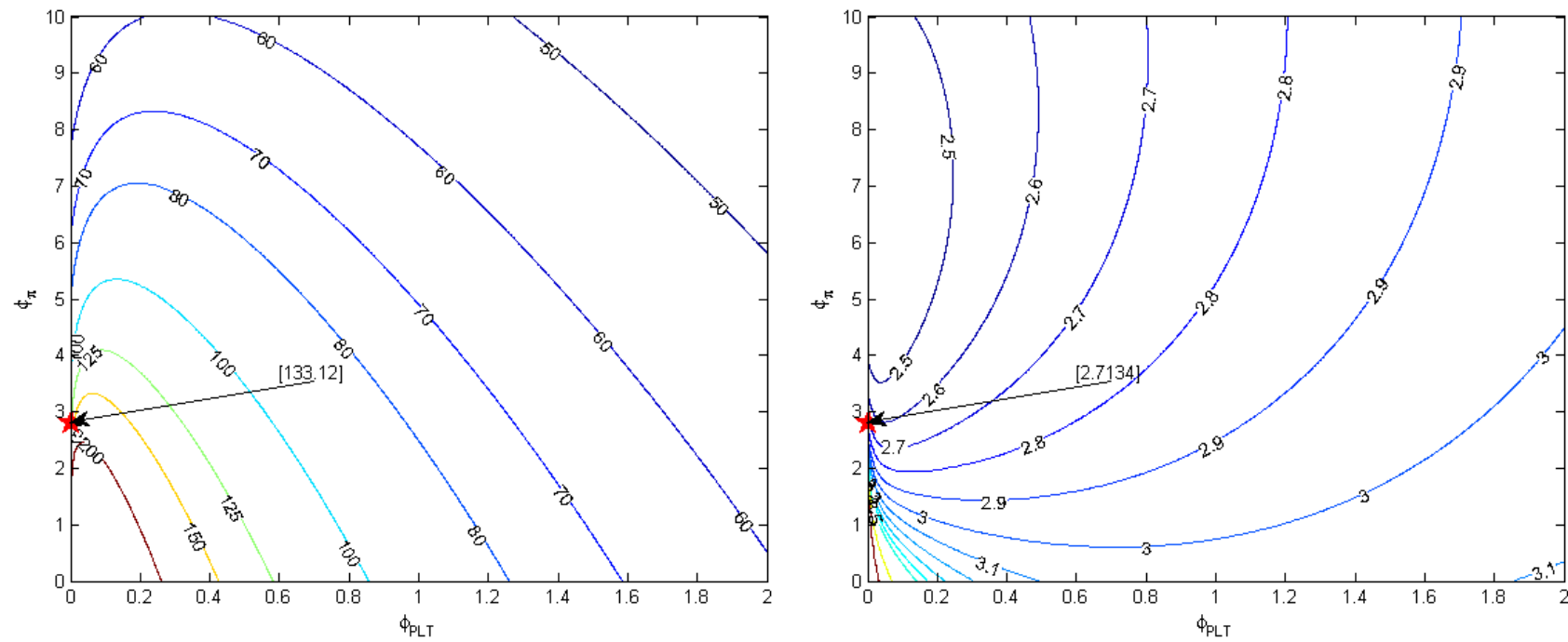

Panel E. Differential responses to sector-specific inflation.
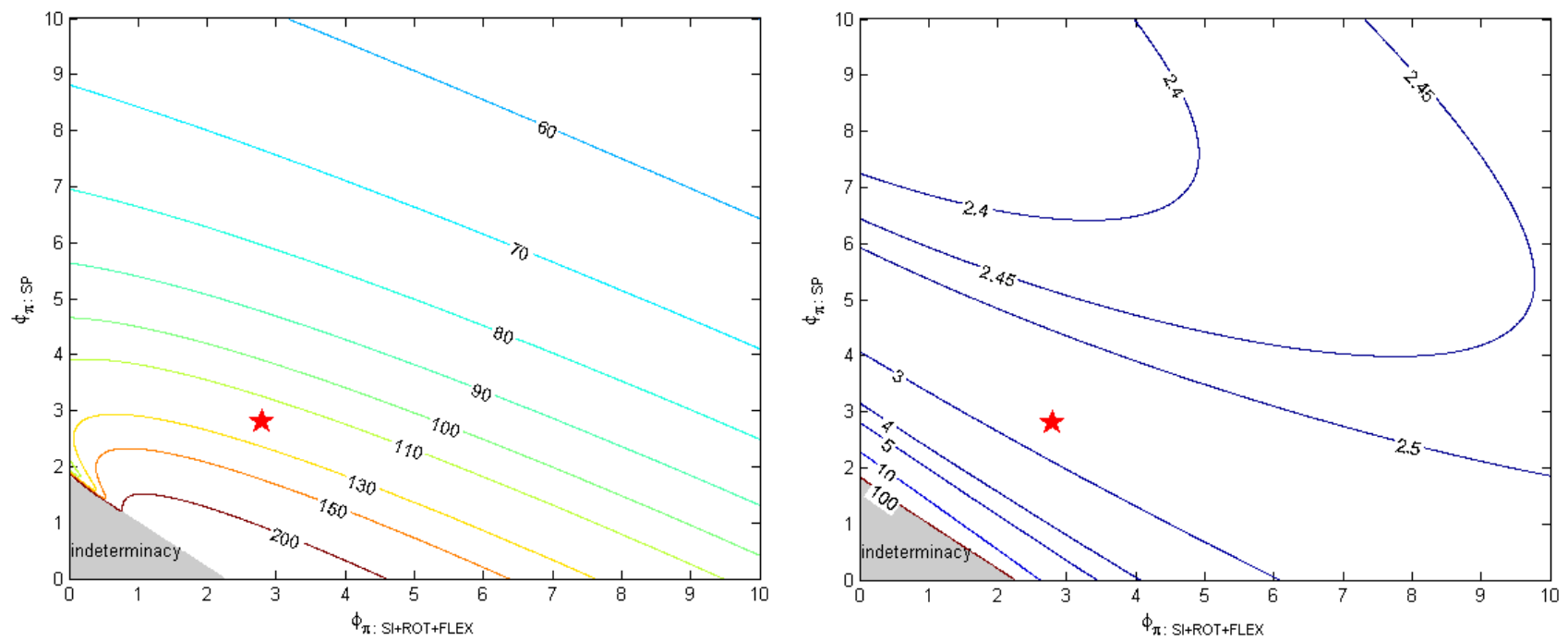

Notes: The figure plots isoloss maps for two welfare functions $L_{1}$ and $L_{2}$ for various combinations of the policy reaction function (Taylor rule). Volatilities of the variables are computed using the parameter estimates of the hybrid model. The red star indicates the position of the estimated Taylor rule. In panels A, B and C, $\phi_{g y}$ on the horizontal axis shows the longrun response of the policy instrument (interest rate) to a unit increase in the output growth rate. On the vertical axis, $\phi_{\pi}$ shows the long-run response of the policy instrument (interest rate) to a unit increase in inflation. Other parameters in the Taylor rule (interest rate smoothing, volatility of the interest rate shock) are held constant. In panel D, the figures in square parentheses show the value of the social loss function evaluated at the estimated Taylor rule. On the horizontal axis, $\phi_{P L T}$ shows the long-run response of the policy instrument (interest rate) to a unit increase in the deviation of the price level from its target. On the vertical axis, $\phi_{\pi}$ shows the long-run response of the policy instrument (interest rate) to a unit increase in inflation. Other parameters in the Taylor rule (interest rate smoothing, volatility of the interest rate shock, output growth rate response) are held constant. In panel E, $\phi_{\pi \text { :SP+ROT+FLEX }}$ on the horizontal axis shows the long-run response of the policy instrument (interest rate) to a unit increase in aggregate inflation in the sticky-information, rule-ofthumb and flexible price sectors. On the vertical axis, $\phi_{\pi \text { :SP }}$ shows the long-run response of the policy instrument (interest rate) to a unit increase in inflation in the sticky-price sector. Other parameters in the Taylor rule (interest rate smoothing, volatility of the interest rate shock, output growth rate response) are held constant. The shaded region shows the Taylor rule parameter combinations associated with equilibrium indeterminacy. 
Appendix Table A1: Initial Parameter Values and Standard Deviations of Shocks

\begin{tabular}{lcccccc}
\hline \hline & $\theta$ & $h$ & $\phi_{\pi}$ & $\phi_{g y}$ & $\rho_{1}$ & $\rho_{2}$ \\
Initial Value & 10 & 0.9 & 3 & 1 & 1.4 & -0.5 \\
St.D. Shocks & & 0.005 & 0.15 & 0.03 & 0.005 & 0.005 \\
\hline & $s_{1}$ & $s_{2}$ & $s_{3}$ & $\delta_{s p}$ & $\delta_{s i}$ & $\rho_{g}$ \\
Initial Value & 0.25 & 0.25 & 0.25 & 0.75 & 0.75 & 0.8 \\
St.D. Shocks & 0.01 & 0.01 & 0.01 & 0.005 & 0.005 & 0.004 \\
\hline & $\sigma_{r}$ & $\sigma_{g}$ & $\sigma_{a}$ & $\sigma_{m e, g y}$ & $\sigma_{m e, \pi}$ & $\sigma_{m e, r}$ \\
Initial Value & 0.5 & 10.0 & 3.0 & 1 & 0.5 & 0.5 \\
St.D. Shocks & 0.0035 & 0.07 & 0.021 & 0.007 & 0.0035 & 0.0035 \\
\hline \hline
\end{tabular}

Note: The table displays the initial values used in MCMC algorithm, as well as the initial standard deviations of shocks used in generating distribution of parameter estimates. 
Appendix Figure A1. Histograms of Baseline Parameters from MCMC.
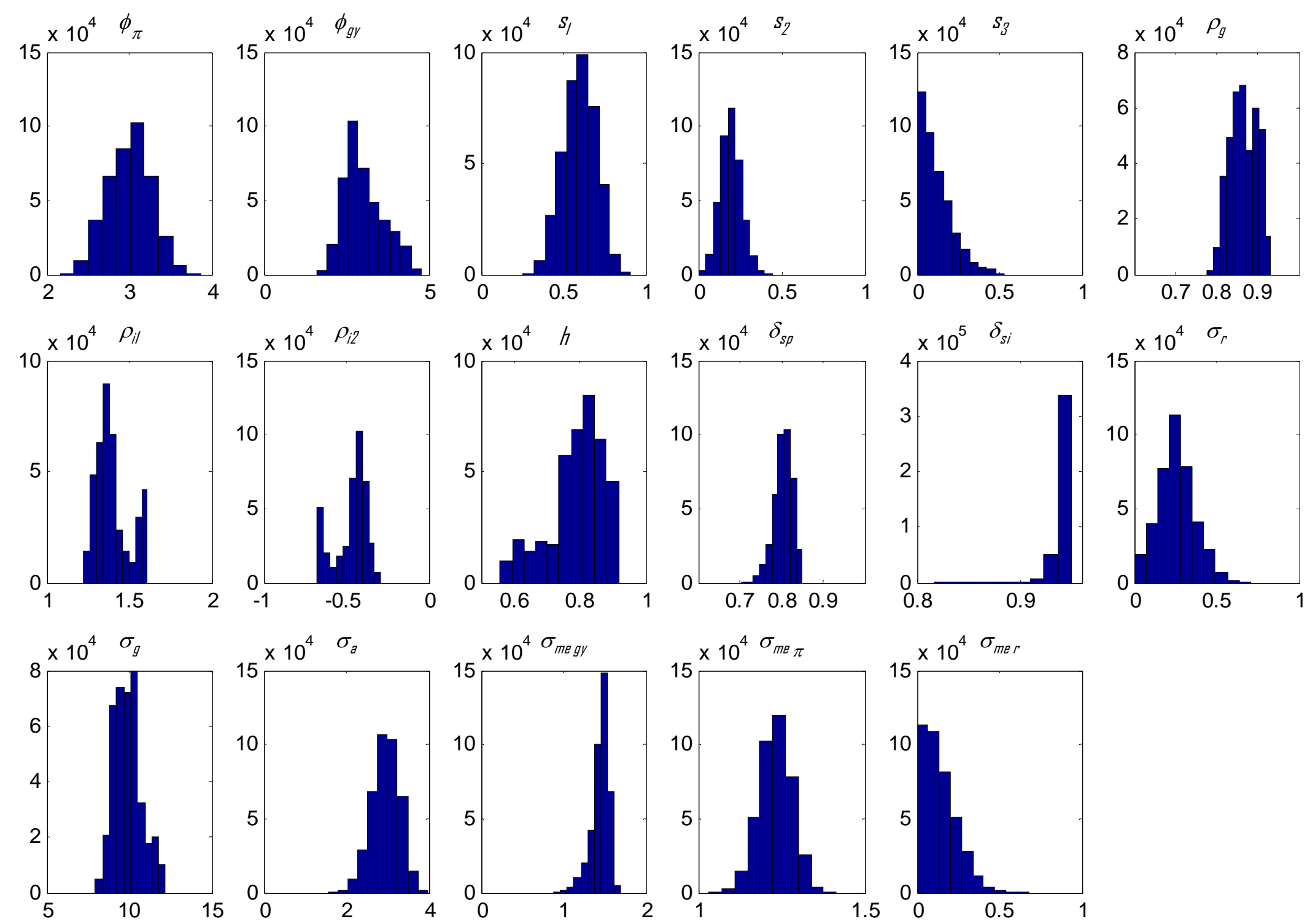

Note: The figure plots the distribution of the last MCMC 400,000 draws of baseline estimation of the hybrid model from Table 1. 
Appendix Figure A2: Shape of Objective Function with respect to each Parameter
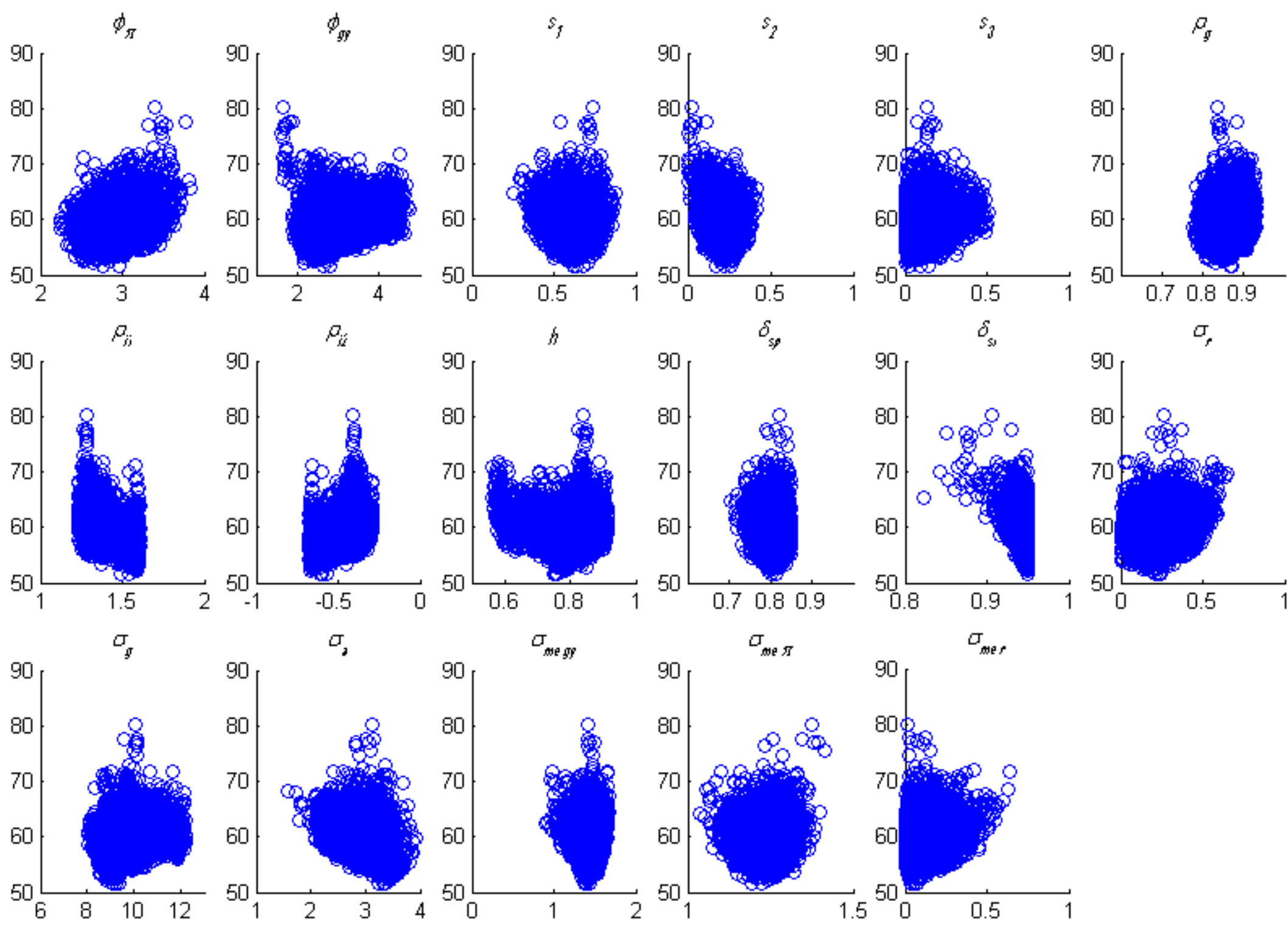

Note: This figure presents scatter plots of values of the objective function associated with parameter values for different draws from the Markov Chain of the baseline estimation of the hybrid model from Table 1. We drop the first 100,000 iterations, then plot every one-hundredth draw from the chain. 
Appendix Figure A3: Between and Within Variances across chains.
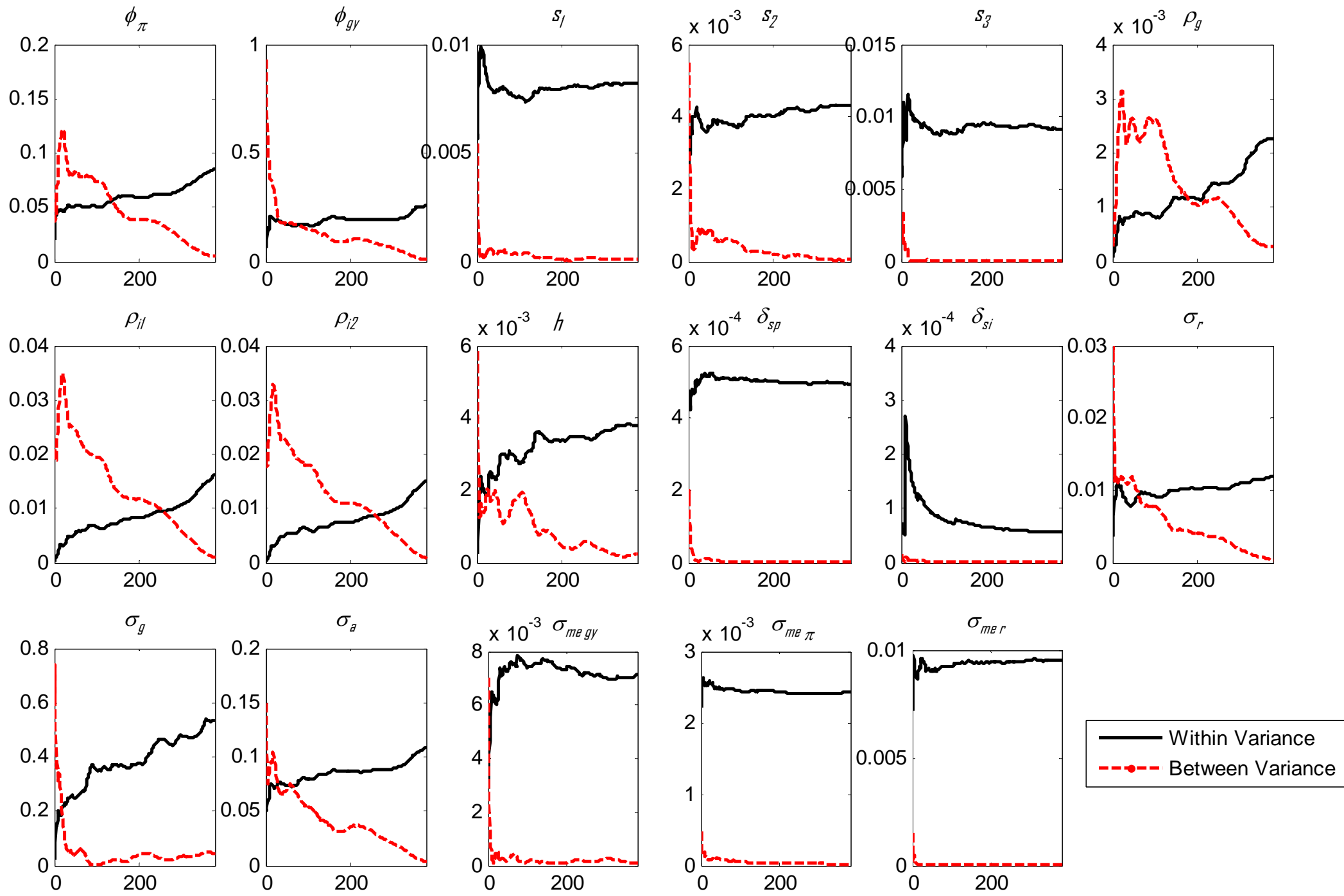

Note: This figure shows the dynamics of between variation of generated chains $B_{N}=\frac{1}{M} \sum_{m=1}^{M}\left(\bar{\Psi}_{(\mathrm{m})}-\bar{\Psi}\right)^{2}$ and within variation across chains $W=\frac{1}{M N} \sum_{m=1}^{M} \sum_{n=1}^{N}\left(\Psi_{(\mathrm{m})}^{(\mathrm{n})}-\bar{\Psi}_{(\mathrm{m})}\right)^{2}$ as a function of chain length $N$ where $\bar{\Psi}_{(\mathrm{m})}=\frac{1}{\mathrm{~N}} \sum_{\mathrm{n}=1}^{\mathrm{N}} \Psi_{(\mathrm{m})}^{(\mathrm{n})}$ is the average of parameter values in chain $m, \bar{\Psi}=\frac{1}{\mathrm{M}} \sum_{\mathrm{m}=1}^{\mathrm{M}} \bar{\Psi}_{(\mathrm{m})}$ is the average of parameter values across chains, $\Psi_{(\mathrm{m})}^{(\mathrm{n})}$ is the parameter value in chain $m$ in draw $n$. In these simulations, $M=4$. The horizontal axis shows the length of the chain in 5000 increments (i.e., 100 corresponds to 500,000 draws). 
Appendix Figure A4: Convergence Statistic $R_{T}$
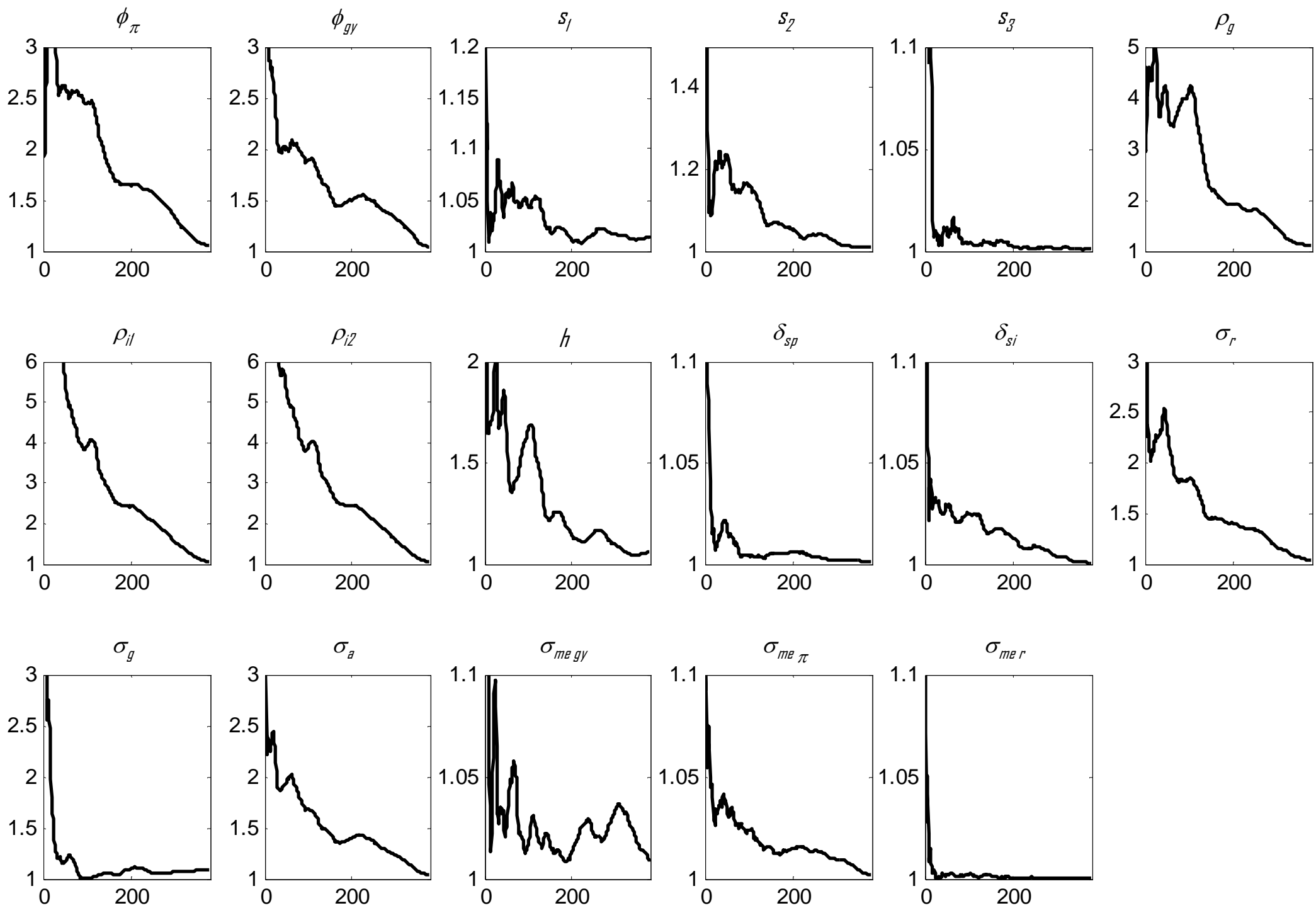

Note: This figure shows the dynamics of $R_{N}=\sqrt{\left(\frac{N-1}{N} W_{N}+B_{N}\right) / W_{N}}$ as a function of chain length $N$ where $B_{N}=\frac{1}{M} \sum_{m=1}^{M}\left(\bar{\Psi}_{(\mathrm{m})}-\bar{\Psi}\right)^{2}$ is the between variation of generated chains, $W=\frac{1}{M N} \sum_{m=1}^{M} \sum_{n=1}^{N}\left(\Psi_{(\mathrm{m})}^{(\mathrm{n})}-\bar{\Psi}_{(\mathrm{m})}\right)^{2}$ is within variation across chains, $\bar{\Psi}_{(\mathrm{m})}=\frac{1}{\mathrm{~N}} \sum_{\mathrm{n}=1}^{\mathrm{N}} \Psi_{(\mathrm{m})}^{(\mathrm{n})}$ is the average of parameter values in chain $m$, $\bar{\Psi}=\frac{1}{\mathrm{M}} \sum_{\mathrm{m}=1}^{\mathrm{M}} \bar{\Psi}_{(\mathrm{m})}$ is the average of parameter values across chains, $\Psi_{(\mathrm{m})}^{(\mathrm{n})}$ is the parameter value in chain $m$ in draw $n$. In these simulations, $M=4$. The horizontal axis shows the length of the chain in 5000 increments (i.e., 100 corresponds to 500,000 draws). 
Appendix Figure A5: Mean Values across Chains
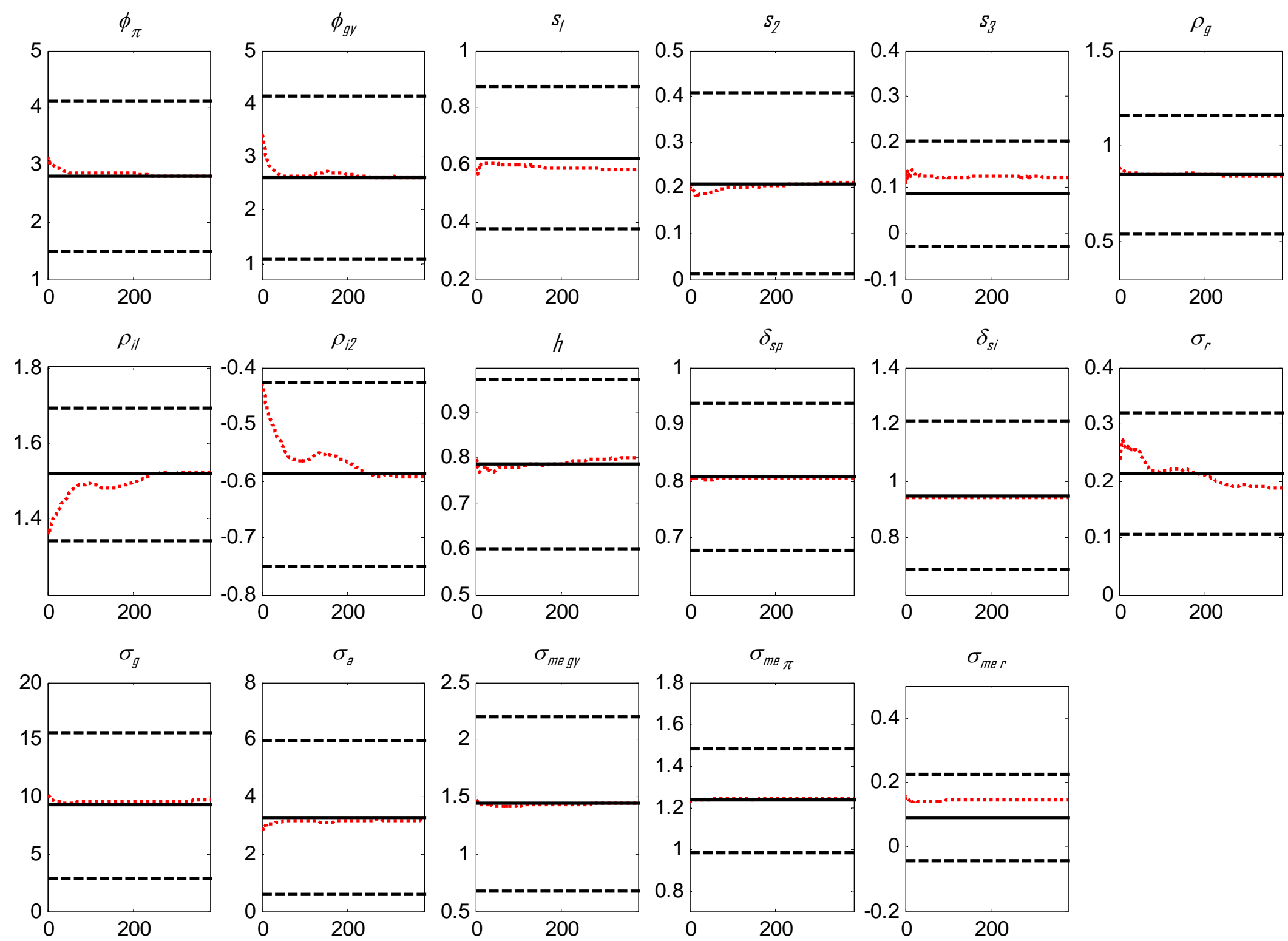

Note: The figure plots our baseline estimate of the hybrid model from Table 1 using 500,000 iterations (solid black line) and two standard error bands (dashed black lines) along with the mean values of parameter estimates across four additional chains (red dotted line), each run for 2 million iterations, dropping the first 100,000 of each. The horizontal axis shows the length of the chain in 5000 increments (i.e., 100 corresponds to 500,000 draws) 
Appendix Figure A6. Baselines volatility maps for key macroeconomic variables.
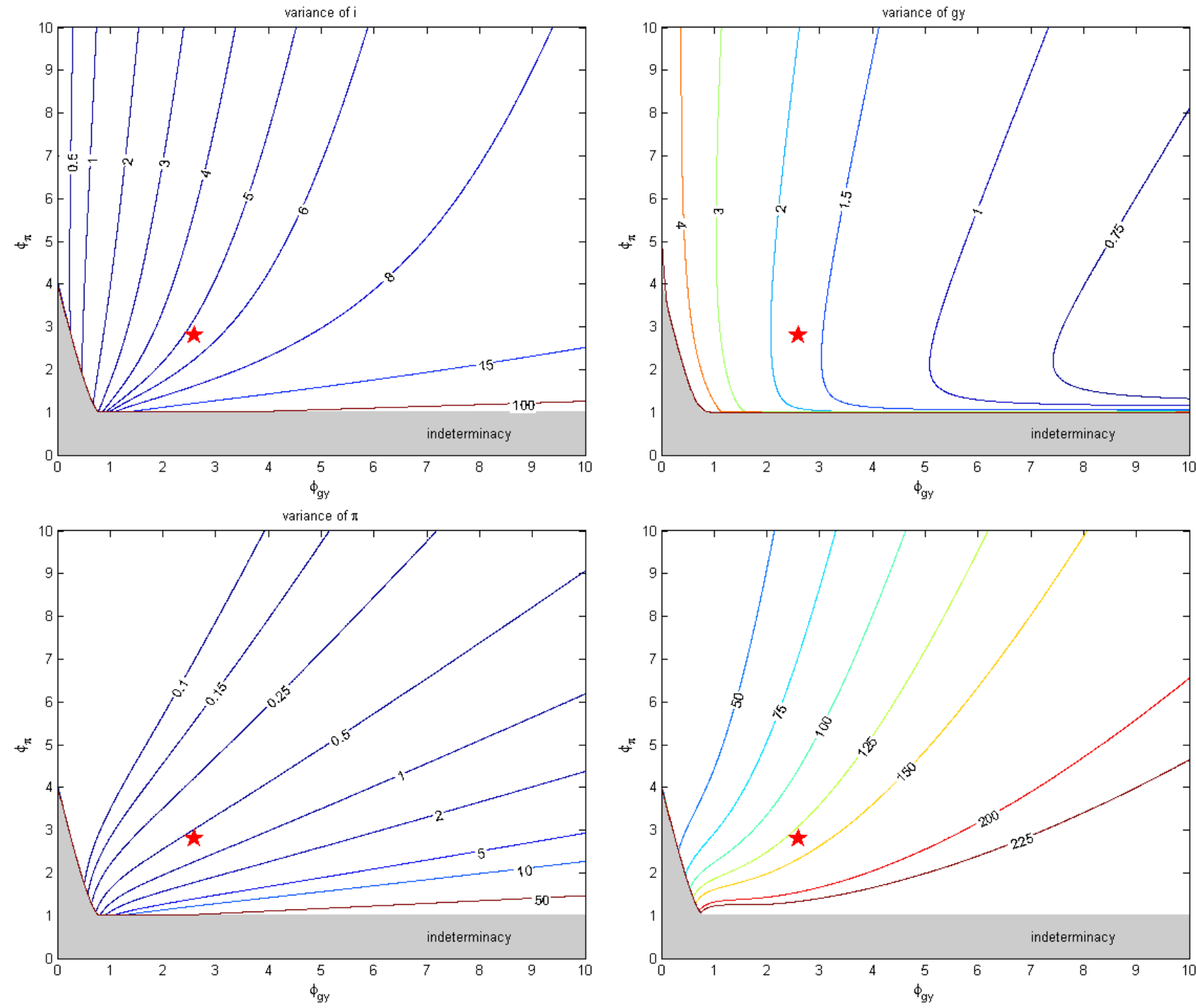

Notes: The figure plot iso-curves for volatility of output growth rate $(g y)$, output gap $(x)$, inflation $(\pi)$ and interest rate $(i)$. On the horizontal axis, $\phi_{g y}$ shows the long-run response of the policy instrument (interest rate) to a unit increase in the output growth rate. On the vertical axis, $\phi_{\pi}$ shows the long-run response of the policy instrument (interest rate) to a unit increase in the inflation. Other parameters in the Taylor rule (interest rate smoothing, volatility of the interest rate shock) are held constant. The red star denotes the combination of $\phi_{g y}$ and $\phi_{\pi}$ corresponding to the estimated Taylor rule. Volatilities of the variables are computed using the parameter estimates of the hybrid model. 
Appendix Figure A7. Price level targeting and volatility maps for key macroeconomic variables.
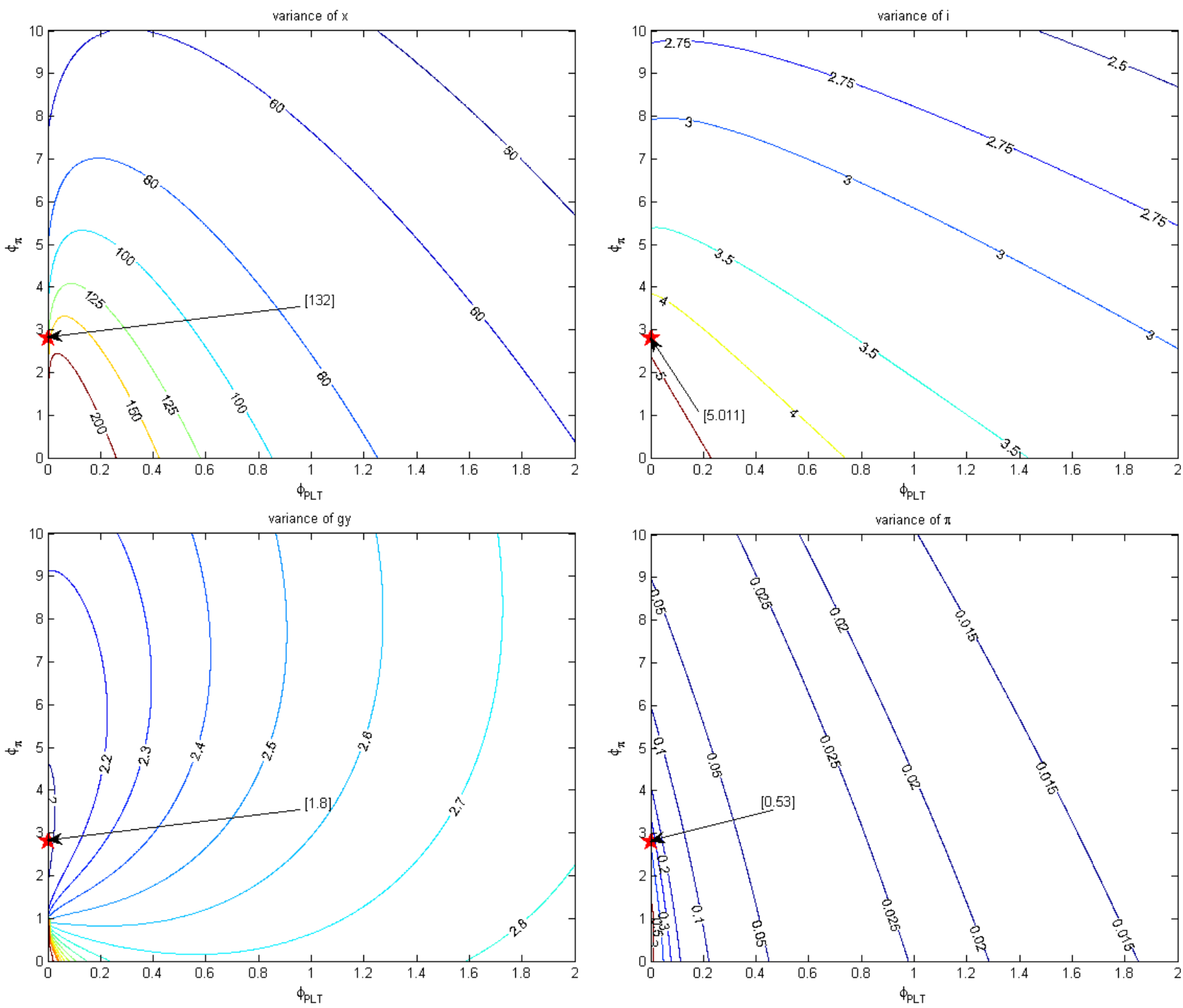

Notes: The figure plot iso-curves for volatility of output growth rate $(g y)$, output gap $(x)$, inflation $(\pi)$ and interest rate $(i)$. On the horizontal axis, $\phi_{P L T}$ shows the long-run response of the policy instrument (interest rate) to a unit increase in the deviation of the price level from its target. On the vertical axis, $\phi_{\pi}$ shows the long-run response of the policy instrument (interest rate) to a unit increase in the inflation. Other parameters in the Taylor rule (interest rate smoothing, volatility of the interest rate shock, output growth rate response) are held constant. The red star denotes the combination of $\phi_{P L T}$ and $\phi_{\pi}$ corresponding to the estimated Taylor rule. The value in squared parentheses shows the level of volatility at the estimated Taylor rule. Volatilities of the variables are computed using the parameter estimates of the hybrid model. 
Appendix Figure A8. Differentiated inflation response and volatility maps for key macroeconomic variables.
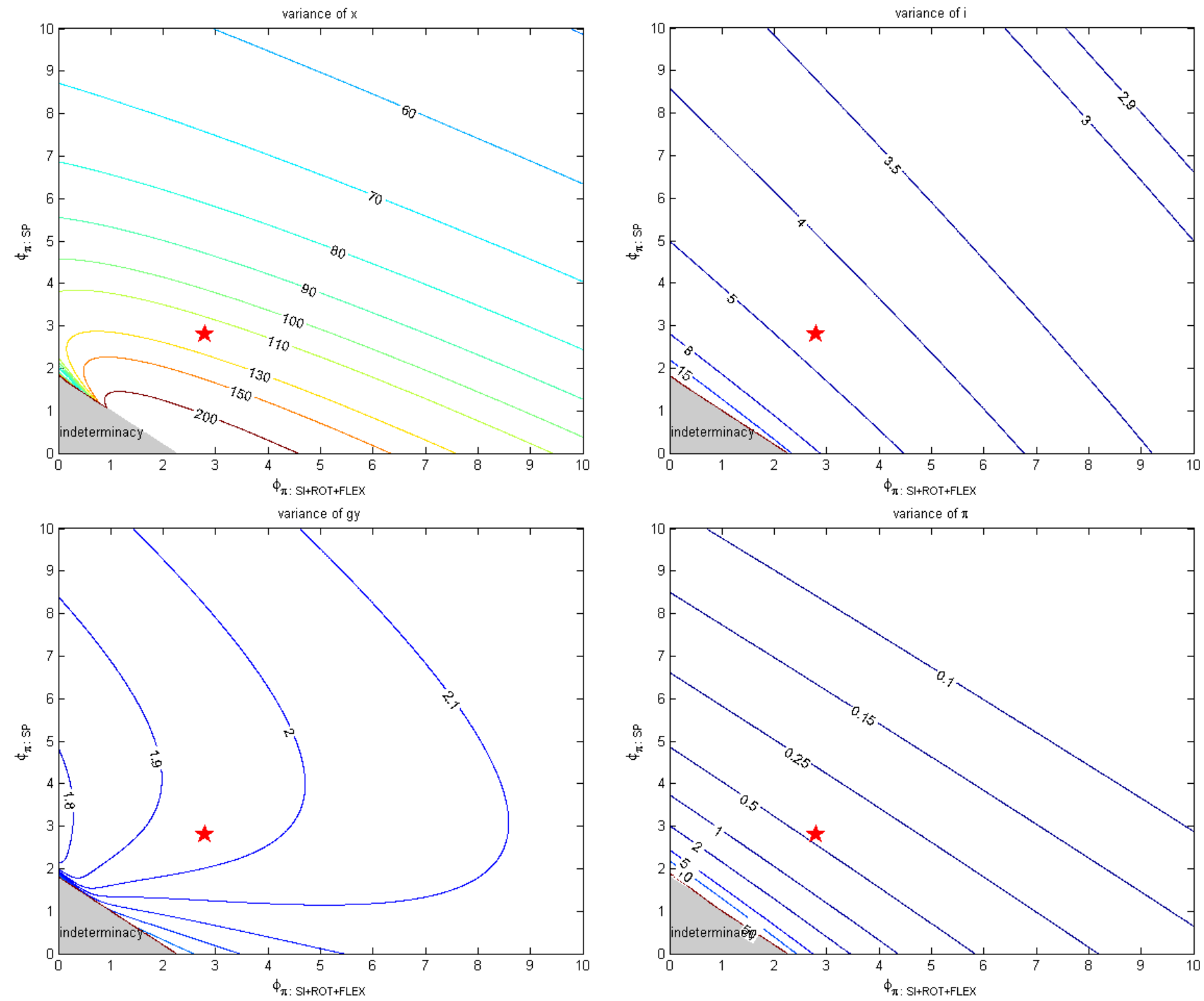

Notes: The figure plot iso-curves for volatility of output growth rate $(g y)$, output gap $(x)$, inflation $(\pi)$ and interest rate $(i)$. On the horizontal axis, $\phi_{\pi \text { SI }+ \text { ROT }+\mathrm{FLEX}}$ shows the long-run response of the policy instrument (interest rate) to a unit increase in the aggregate inflation in the sticky-information, rule-of-thumb and flexible price sectors. On the vertical axis, $\phi_{\pi \mathrm{SP}}$ shows the long-run response of the policy instrument (interest rate) to a unit increase in the inflation in the sticky-price sector. Other parameters in the Taylor rule (interest rate smoothing, volatility of the interest rate shock, output growth rate response) are held constant. The red star denotes the combination of $\phi_{\pi \text { SI }+\mathrm{ROT}+\mathrm{FLEX}}$ and $\phi_{\pi \mathrm{SP}}$ corresponding to the estimated Taylor rule where $\phi_{\pi \mathrm{SI}+\mathrm{ROT}+\mathrm{FLEX}}=\phi_{\pi \mathrm{SP} \text {. }}$. Volatilities of the variables are computed using the parameter estimates of the hybrid model. 
Appendix Figure A9. Welfare isoloss maps for alternative values for the weight on output volatility.

Loss function $L_{1}$
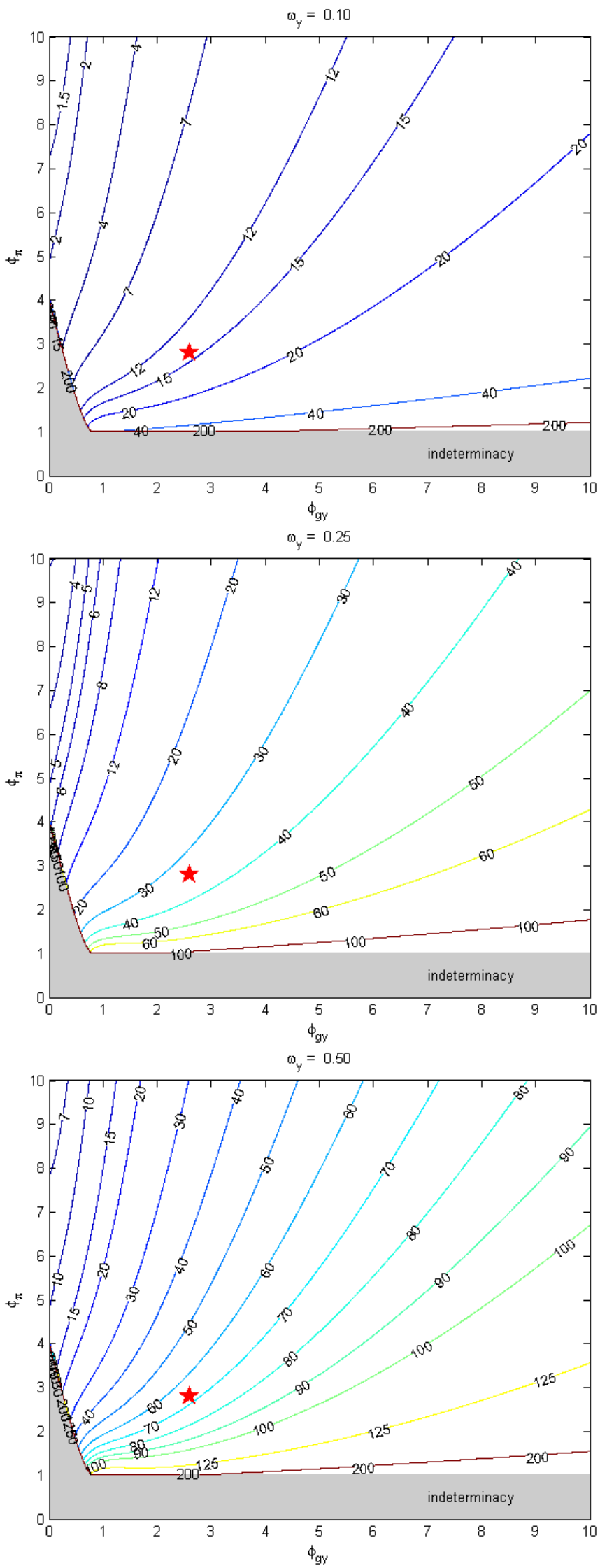

Loss function $L_{2}$
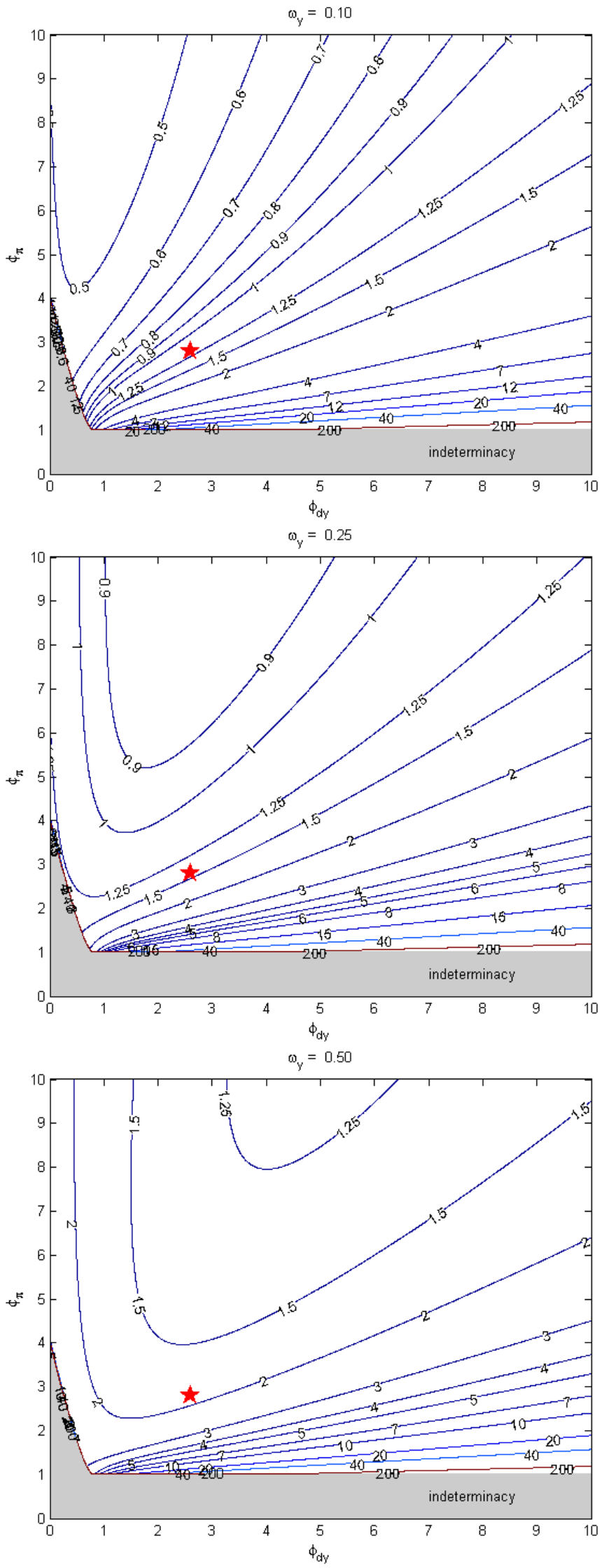